\title{
The Effect of Growth Factors and Soluble Nogo-66 Receptor Protein on Transplanted Neural Stem/Progenitor Survival and Axonal Regeneration After Complete Transection of Rat Spinal Cord
}

\author{
Xiaodong Guo, ${ }^{*} \dagger$ Tasneem Zahir, $\neq$ Andrea Mothe, $\dagger$ Molly S. Shoichet, $\neq$ \\ Cindi M. Morshead, § Yusuke Katayama, $\$$ and Charles H. Tator $\dagger$ \\ *Department of Orthopaedics, Union Hospital, Tongji Medical College, Huazhong University of Science and Technology, \\ Wuhan, P.R. China \\ $\dagger$ Toronto Western Research Institute, Toronto Western Hospital and University of Toronto,Toronto, Ontario, Canada \\ $¥$ Department of Chemical Engineering \& Applied Chemistry, Terrence Donnelly Centre for Cellular and Biomolecular Research, \\ University of Toronto, Toronto, Ontario, Canada \\ $\S$ Department of Surgery and Institute of Medical Sciences, Terrence Donnelly Centre for Cellular and Biomolecular Research, \\ University of Toronto, Toronto, Ontario, Canada
}

\begin{abstract}
Adult central mammalian axons show minimal regeneration after spinal cord injury due to loss of oligodendrocytes, demyelination of surviving axons, absence of growth-promoting molecules, and inhibitors of axonal outgrowth. In the present study, we attempted to address these impediments to regeneration by using a combinatory strategy to enhance cell survival and regeneration after complete spinal cord transection (SCT) in adult rats. The strategy comprised: 1) adult rat brain-derived neural stem/progenitor cells (NSPCs) preseeded on laminin-coated chitosan channels; 2) extramedullary chitosan channels to promote axonal regrowth and reduce the barrier caused by scarring; 3) local delivery of a novel rat soluble Nogo-66 receptor protein $[\mathrm{NgR}(310)$ ecto-Fc, referred to as $\mathrm{NgR}]$ to block the inhibitory effect of myelin-based inhibitors; and 4) local delivery of basic fibroblast growth factor, epidermal growth factor, and platelet-derived growth factor to enhance survival and promote differentiation of transplanted cells. Compared with our previous studies where brain-derived NSPCs preseeded in extramedullary chitosan channels were implanted in the same SCT model but without growth factors and $\mathrm{NgR}$, the present channel-growth factor combination produced greater numbers of surviving NSPCs after SCT. Also, the growth factors promoted preferential differentiation of NSPCs toward oligodendrocytes, while NgR significantly decreased astrocytic differentiation of NSPCs. $\mathrm{NgR}$ alone or in combination with NSPCs significantly enhanced the total number of myelinated fibers in the bridge and increased the area of the bridging tissue between the cord stumps. The combination of $\mathrm{NgR}$, growth factors, and NSPCs had synergistic effect on bridge formation. However, only a small number of descending corticospinal tract axons grew into the central portions of the bridges as shown by anterograde tracing of the corticospinal tract with BDA. The majority of the regenerated axons in the channels originated from local host neurons adjacent to the tissue bridges. In conclusion, we showed that growth factors increased survival of transplanted NSPCs whereas NgR enhanced axonal regeneration, but the combination did not have additive effects on functional recovery or regeneration.
\end{abstract}

Key words: Spinal cord injury (SCI); Neural stem/progenitor cells (NSPCs); Nogo; Nogo-66 receptor; Chitosan channel; Axonal regeneration

\section{INTRODUCTION}

In contrast to mammalian peripheral axons and developing central axons, adult mammalian central axons show minimal functionally relevant regeneration. In the injured adult mammalian central nervous system (CNS), there is also extensive loss of oligodendrocytes, demyelination of surviving axons, a lack of growth-promoting molecules, inhibitors of axonal outgrowth in CNS myelin, and astroglial "scar" formation that suppresses regeneration (2).

Transplantation of adult neural stem/progenitor cells (NSPCs) is one of the most promising experimental strategies for repair of spinal cord injury (SCI) $(1,23,38$, $42,44)$ and some human trials have been undertaken to test efficacy of this approach (57). These multipotential

Received October 7, 2009; final acceptance July 19, 2011. Online prepub date: January 10, 2012.

Address correspondence to Charles H. Tator, Ph.D., M.D., Toronto Western Research Institute, Toronto Western Hospital and University of Toronto, Room 12-435, McLaughlin Wing, 399 Bathurst St., Toronto, Ontario, Canada M5T 2S8. Tel: (416) 603-5889; Fax: (416) 603-5298;

E-mail: charles.tator@uhn.on.ca 
adult stem cells are capable of self-renewal and differentiation into mature neural cells such as oligodendrocytes, astrocytes, or neurons $(1,43,49,67,68)$. However, there has been poor survival and differentiation of transplanted NSPCs in the adult mammalian CNS, especially at the injury epicenter. To counter these multiple impediments to regeneration, combination strategies are being pursued and include the provision of cellular scaffolds to replace necrotic tissue $(6,48)$, the delivery of neuroprotective agents $(19,20,24)$, and growth factors $(20,61$, 72) to limit secondary injury, and to neutralize the inhibitory environment present after injury (9).

Our research team is developing an entubulation strategy for SCI repair, which comprises a biodegradable chitosan channel, a localized drug delivery system (DDS), and NSPCs $(14,19,22,40,41,46,59,60,71)$. The tubular construct presents a pathway for guided axonal growth and tissue regeneration while at the same time providing a mechanism for local delivery of cells and therapeutically relevant biomolecules. The channels provide an environment that is permissive to regeneration and also prevents ingrowth of fibrous tissue that would otherwise block the path of regenerating axons.

SCI results in the loss of oligodendrocytes and demyelination of surviving axons such as in the subpial rim in incomplete injuries, and since spontaneous remyelination is limited, restoration of the oligodendrocyte population by cell replacement therapy is an attractive strategy for promoting remyelination after SCI $(2,17$, $21,24,25,38)$. Recently, our group reported that an implanted extramedullary chitosan channel seeded with NSPCs promoted long-term survival of the transplanted cells and resulted in tissue bridge formation after complete spinal cord transection (SCT), the most severe experimental SCI. At 5 weeks postinjury, $23.2 \%$ of the cells differentiated into $\mathrm{CC} 1$-positive oligodendrocytes (71). However, only $17.4 \%$ of the cells were oligodendrocytic after 14 weeks and minimal axonal regeneration was observed (42).

Our group and others found that the combination of growth factors such as basic fibroblast growth factor (bFGF), epidermal growth factor (EGF), and plateletderived growth factor (PDGF) not only enhanced survival of the transplanted NSPCs but also promoted oligodendrocytic differentiation $(21,25)$. PDGF-AA is one of the most powerful growth factors for stimulating differentiation into oligodendrocytes $(15,26,47)$ and promoting survival of newly formed oligodendrocytes $(7,8)$. With the combination of bFGF/EGF/PDGF, KarimiAbdolrezaee et al. (21) found that $37 \%$ of the transplanted mouse brain-derived NSPCs survived and, of these, $33 \%$ formed mature oligodendrocytes at 8 weeks post-SCI. In this model the NSPCs were transplanted into the white matter of the spinal cord in the subacute stage after clip compression SCI and improved the functional recovery over controls.

After SCI, severed axons show poor regrowth because there are many inhibitors of axonal regeneration in the adult mammalian CNS including myelin-derived inhibitors $(9,35,53)$ and glial scar-derived chondroitin sulfate proteoglycans $(4,10,13,56)$. Three kinds of myelin-associated inhibitory proteins, Nogo-A $(5,9,31)$, myelin-associated glycoprotein (MAG) (12,32), and oligodendrocyte myelin glycoprotein (OMgp) $(11,65)$ activate the Nogo-66 receptor and inhibit axonal regeneration. The Nogo-66 receptor binds all three myelinderived inhibitors, and is an attractive therapeutic target because of its key role in the inhibition of axonal regeneration, high-affinity interactions, and neural specificity. Other pharmacological methods of inhibition such as blockade of Rho and Rho-associated protein kinase (ROCK) signaling can block myelin inhibitors and glial scar inhibition but these signaling molecules are present in all cells in the body, and thus specificity is a concern $(9,55)$. Importantly, a novel Ig-fusion protein containing the ligand binding domain of Nogo-66 receptor 1 [aa 27-310, $\mathrm{NgR}$ (310)ecto-Fc, referred to as $\mathrm{NgR}$ ] was recently reported to block the inhibitory effect of all three myelin-derived inhibitors in vitro and in vivo $(9,28,29)$. When $\mathrm{NgR}$ was administered intrathecally to rats with SCI, there was enhanced axonal growth in the corticospinal and raphespinal tracts, accompanied by improved functional recovery (29). Thus, targeting the $\mathrm{NgR} 1$ pathway with a soluble Nogo-66 receptor protein may be a more effective strategy to promote central axonal regeneration.

The present study implements a combination of strategies to address the multiple impediments to regeneration after complete SCT at T8 in adult rats. We have combined: 1) multipotential adult rat brain-derived NSPCs with the capacity to differentiate into mature neural cells including oligodendrocytes, astrocytes, and neurons; 2) an extramedullary chitosan tube to serve as a guidance channel for regenerating axons and provide a bridge between the spinal cord stumps; 3) $\mathrm{NgR}$ to block the inhibitory effect of all three myelin-derived inhibitors and enhance axon regeneration; and 4) growth factors including bFGF, EGF, and PDGF to enhance transplanted cell survival and promote oligodendrocytic differentiation. In comparison with our previous studies of extramedullary implanted chitosan channels preseeded with the same adult rat brain-derived NSPCs in the same SCT model but without the delivery of growth factors and $\mathrm{NgR}$ (42), we found that the present combination of NSPCs in guidance channels containing growth factors and the Nogo-66 receptor protein enhanced long-term transplant survival, caused a twofold increase in oligodendrocytic differentiation, and 
produced greater axonal regeneration. To our knowledge, this is the first study that combines NSPC transplantation with an agent to combat myelin-based inhibitors after SCI.

\section{MATERIALS AND METHODS}

\section{Preparation of Chitosan Channels}

Chitosan channels were prepared as previously described, with minor alterations (14). Briefly, chitosan chloride (Protosan UP CL213, NovaMatrix) was dissolved in distilled water then precipitated with a $4 \%$ $\mathrm{NaOH}$ solution, filter washed, and lyophilized. The dried chitosan was made into a $3 \%$ solution in $2 \%$ acetic acid, followed by $50: 50$ dilution in ethanol, and stored at $4^{\circ} \mathrm{C}$.

Channels were prepared in $15-\mathrm{cm}$-length cylindrical glass molds, made by inserting an inner glass rod $(\mathrm{OD}=$ $4 \mathrm{~mm}$ ) into a larger glass channel (ID $=8 \mathrm{~mm}$ ). The inner rod was fixed in place at both ends by rubber septa. To form chitin channels, $83 \mu \mathrm{l}$ acetic anhydride was added to $5 \mathrm{ml}$ chitosan solution, vortexed, vacuumed to remove air bubbles, then injected into the molds. After $24 \mathrm{~h}$, the chitin channels were removed from the outer mold and washed in distilled water for an additional $24 \mathrm{~h}$. The chitin channels were converted back into chitosan by three consecutive hydrolysis cycles $\left(2 \mathrm{~h}, 110^{\circ} \mathrm{C}\right)$ in $28.6 \mathrm{wt} \% \mathrm{NaOH}$ solution, with rinsing between cycles. After another 24-h wash, the chitosan channels were removed from the glass rods and air-dried over stainless steel cylindrical cores $(\mathrm{OD}=3.7$ $\mathrm{mm})$. The OD of the channels was $4 \mathrm{~mm}$ and ID was $3.7 \mathrm{~mm}$. The degree of deacetlyation of the chitosan channels was $89 \%$ as determined by ${ }^{1} \mathrm{H}$-nuclear magnetic resonance (NMR) spectroscopy (14).

Channels were rehydrated in water, removed from the steel core, and cut to 10-mm lengths. A small "v" was cut in the ventral aspect of the channel at the rostral and caudal ends, so that the length of the dorsal surface of the channel was $10 \mathrm{~mm}$ and the ventral surface was 8 $\mathrm{mm}$. In a pilot experiment we found that this modification of the channels allowed us to reduce the gap between stumps from an average of $3.5 \mathrm{~mm}$ to $2 \mathrm{~mm}$ because there was less elevation of the stumps as they entered the channel. The channels were sterilized by ethylene oxide gas.

\section{Animals}

Adult female wild-type Sprague Dawley (SD) rats (200-300 g, Charles River, St. Constant, Quebec, Canada,) and adult enhanced green fluorescent protein (GFP)-expressing Wistar rats [strain; Wistar-TgN(CAGeGFP)184ys, bred in the laboratory of Dr. A. Keating, Toronto, Canada, 200-360 g] were used in this study. The transgenic rats were originally obtained from the
YS Institute, Inc., Utsunomiya, Tochigi, Japan. The animal protocols were approved by the Animal Care Committee of the Research Institute of the University Health Network in accordance with policies established by the Canadian Council of Animal Care.

\section{Isolation and Culture of Adult Rat Brain-Derived NSPCs}

Adult rat brain-derived NSPCs were isolated from the subependymal region of the lateral ventricles of adult transgenic rat forebrains expressing GFP as previously described (49,71). NSPCs cultured from these rats have been shown to stably express the GFP transgene long term both in vitro and in vivo (37). Briefly, subependymal tissue was harvested from 8-12-week-old rats and subjected to papain dissociation (Papain Dissociation System; Worthington Biochemical Corporation, Lakewood, NJ). The resultant cell suspension was centrifuged and the pelleted cells were subjected to a discontinuous density gradient to remove cell debris and resuspended in complete medium (CM) containing Neurobasal media (Gibco-Invitrogen, Burlington, ON, Canada), B27 neural supplement (Gibco-Invitrogen), $2 \mathrm{mM}$ L-glutamine (Sigma-Aldrich), $100 \mu \mathrm{g} / \mathrm{ml}$ penicillinstreptomycin (Sigma-Aldrich), $20 \mathrm{ng} / \mathrm{ml}$ epidermal growth factor (recombinant human EGF; GibcoInvitrogen), $20 \mathrm{ng} / \mathrm{ml} \mathrm{bFGF} \mathrm{(recombinant} \mathrm{human} \mathrm{bFGF;}$ Gibco-Invitrogen), and $2 \mu \mathrm{g} / \mathrm{ml}$ heparin (SigmaAldrich). Cell numbers and viability were determined with a hemocytometer and trypan blue exclusion test. Dissociated cells were plated in complete media and incubated at $37^{\circ} \mathrm{C}$ in an incubator with $5 \% \mathrm{CO}_{2}$. GFPpositive neurospheres appeared in 2-3 weeks after which cells were passaged every week.

\section{Seeding of NSPCS Into Chitosan Channels}

Sterile chitosan channels were coated with $5 \mu \mathrm{g} / \mathrm{ml}$ of laminin solution (Gibco-Invitrogen) and incubated in complete media overnight, prior to cell seeding. Next, these channels were transferred into empty wells and the media inside the tubes replaced with $80 \mu \mathrm{l}$ of cell suspension, containing GFP-positive neurospheres (passage 4 ) at a cell density of $1 \times 10^{6} /$ cells/80 $\mu 1$. For the in vivo study, the channels containing the neurosphere suspension were rotated manually every $15 \mathrm{~min}$ for $1 \mathrm{~h}$ to produce uniform cell seeding. These channels were then transferred to new wells containing complete media and incubated for 2 days prior to implantation into the transected spinal cords. After 2 days in vitro, the neurospheres had adhered to the inner lining of the chitosan channel, formed uniform multicellular sheets (approximately $100 \mu \mathrm{m}$ thick), and the cell density increased to $1.5 \pm 0.10 \times 10^{6}$ cells per channel. However, due to gravity the cell lining of the channels was not uniform and covered mainly the lower half of the channels. The 
initial cell density was evaluated by enzymatic dissociation of neurospheres into single cells and trypan blue exclusion. The cells were counted with a hemocytometer.

\section{Rat-Soluble Nogo-66 Receptor [27-310]-Fc Fusion Protein $(\mathrm{NgR})$}

$\mathrm{NgR}(310)$ ecto-Fc (referred to as $\mathrm{NgR}$ ) designated as AA-rat soluble Nogo-66 receptor [27-310]-Fc was a kind gift from Dr. Daniel Lee of Biogen Idec Inc. (Cambridge, MA). It contained largely amino acid residues 27-310 of the rat Nogo-66 receptor fused to rat IgG1-Fc, and was produced from $\mathrm{CHO}$ cells with full glycosylation, purified to $>99 \%$, and verified by mass spectrometry. The generation and characterization of the rat Nogo receptor [27-310]-Fc fusion protein has been described previously $(28,29)$. The new molecule used in the present study was developed by Lee et al. and contained two alanine substitutions in the non-ligand binding domain of the Nogo receptor molecule. The two substitutions did not alter the antibody recognition epitopes, myelin ligand binding, electrophoretic mobilities, or performance in the in vitro myelin-dependent neurite outgrowth assay (31).

\section{Groups}

Rats were divided into seven treatment groups as shown in Table 1 with varying combinations of NSPCs, growth factors bFGF/EGF/PDGF (referred to as GF), or $\mathrm{NgR}$ (310)ecto-Fc (referred to as $\mathrm{NgR}$ ). In groups 1-3, the chitosan channels were seeded with NSPCs, while groups 4-6 had channels without NSPCs. Group 1 received a combination of all three strategies including chitosan channels, NSPCs, GF, and NgR (designated channel + NSPCs + GF + NgR). Group 2 was channel + $\mathrm{NSPCs}+\mathrm{GF}$, and group 3 was channel + NSPCs + NgR . Group 4 was identical to group 2 except without NSPCs (channel + GF). Group 5 was identical to group 3 except without NSPCs (channel $+\mathrm{NgR}$ ). Group 6 received only the chitosan channel. Group 7 received channel + NSPCs and served as a control for analysis of the survival and differentiation of NSPCs. The number of animals and methods of analysis are shown in Table 1.

\section{Complete Transection Injury of the Spinal Cord}

A total of 72 rats were used in this study, and all were kept at a 12-h light/dark cycle and received water and food ad libitum. A complete SCT injury model ensured that any axons in the channels were regenerated axons. Rats were anesthetized with $2 \%$ halothane and 1 : 2 nitrous oxide/oxygen. Eye lubricant (Optimyxin), was applied to protect the eyes, and $5 \mathrm{ml}$ of saline was injected subcutaneously preoperatively. With the aid of an operating microscope, the T7-9 laminae were removed, the facets at the same levels were removed, and the dura mater was longitudinally incised in the midline and then excised at T8. The adjacent dorsal and ventral nerve roots were transected to allow the transected stumps to be mobilized for insertion into the channel. The spinal cord at the T8 level was elevated in a dorsal direction with a blunt hook, and then completely transected with microscissors, followed by reinspection to ensure complete transection of the spinal cord and all adjacent spinal roots. A thin piece of absorbable gelatin sponge (Surgifoam; Ethicon, Inc., Soeborg, Denmark) was placed in the gap between the two stumps for hemostasis when necessary. After SCT and hemostasis, the gap between the two stumps of the spinal cord was approximately $1.5-2.5 \mathrm{~mm}($ mean $=2$ $\mathrm{mm})$. A blunt hook inserted under the rostral stump was then used to lift the stump and insert it into the channel. This procedure was repeated for insertion of the caudal stump into the channel. The stumps were inserted approximately $2.5 \mathrm{~mm}$ into the ends of the channel, and the remaining gap between the stumps in the channel

Table 1. Number of Rats Used for Immunohistochemistry (IHC), Histology, Axon Counts, and TEM Analysis in Each Group

\begin{tabular}{lccccc}
\hline Groups & $\begin{array}{c}\text { No. of } \\
\text { Rats }\end{array}$ & $\begin{array}{c}\text { IHC } \\
\text { (Frozen) }\end{array}$ & $\begin{array}{c}\text { Axon Counts } \\
\text { (Resin Embedded) }\end{array}$ & $\begin{array}{c}\text { Histology } \\
\text { (Paraffin) }\end{array}$ & TEM \\
\hline 1. Channel + NSPCs + GF + NgR & 13 & 8 & 3 & 1 & 1 \\
2. Channel + NSPCs + GF & 12 & 6 & 4 & 1 & 1 \\
3. Channel + NSPCs + NgR & 11 & 6 & 4 & 1 & \\
4. Channel + GF & 11 & 5 & 4 & 1 & 1 \\
5. Channel + NgR & 10 & 4 & 4 & 2 & 1 \\
6. Channel & 12 & 5 & & & \\
7. Channel + NSPCs & 3 & 3 & 23 & 7 & 5 \\
Total & 72 & 37 & & & \\
\hline
\end{tabular}

Channel, laminin-coated chitosan channel; NSPCs, neural stem/progenitor cells; GFm bFGF/EGF/PDGF combination; $\mathrm{NgR}, \mathrm{NgR}(310)$ ecto-Fc, a novel rat-soluble Nogo-66 receptor [27-310]-Fc fusion protein. 

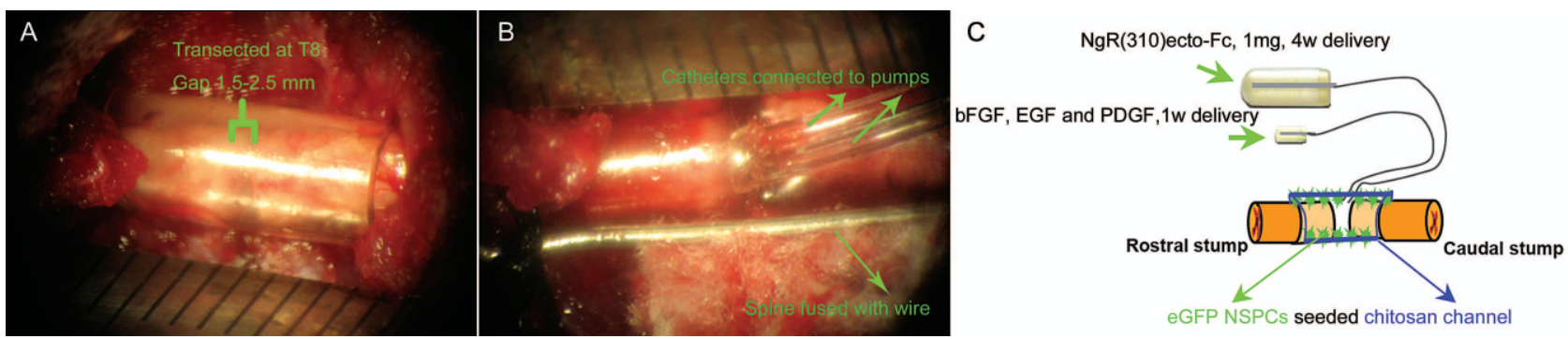

Figure 1. Surgical procedure for extramedullary chitosan channel implantation after spinal cord transection. (A, B) After Laminectomy at T7-9, chitosan channels seeded with GFP NSPCs were implanted on day 0 after complete spinal cord transection at T8. The spine was fused with wire from T6-10 (A). Two different-sized osmotic pumps were used to deliver the GFs and NgR (B) as outlined in the text. (C) Schematic drawing displays the surgical procedure for placement of the seeded channels and the catheters and pumps.

was approximately $2 \mathrm{~mm}$ (Fig. 1). The small "v"-shaped defect in the ventral ends of the channels minimized elevation of the stumps at their entrance into the channel. A spinal fusion was then performed from T6 to T10 with surgical wire and 2-0 silk so that there was a wire bridge along both the right and left dorsolateral aspects of the spinal cord (Fig. 1B).

\section{Local Delivery of NgR and Growth Factors}

Two different-sized osmotic pumps were used to deliver the GFs and NgR (Fig. 1C). To promote axonal regeneration, $1 \mathrm{mg} \mathrm{NgR} \mathrm{(29)} \mathrm{in} \mathrm{PBS} \mathrm{solution} \mathrm{was} \mathrm{deliv-}$ ered for 4 weeks to groups 1,3 , and 5 by an osmotic pump (Alzet 2ML4; $2 \mathrm{ml}$ volume, $2.5 \mu \mathrm{l} / \mathrm{h}$ ). To enhance the survival of the transplanted cells, a mixture of GFs including human recombinant bFGF $(3 \mu \mathrm{g} / 100 \mu \mathrm{l}$; Invitrogen), human recombinant EGF $(3 \mu \mathrm{g} / 100 \mu \mathrm{l}$; Invitrogen), and rat recombinant PDGF-AA $(1 \mu \mathrm{g} / 100$ $\mu \mathrm{l}$; R\&D System) in a PBS solution containing $100 \mu \mathrm{g} /$ $\mathrm{ml}$ rat serum albumin (Sigma, St. Louis, MO) was delivered for 7 days in groups 1, 2, and 4 using an osmotic minipump (model 1007D, $0.5 \mu \mathrm{l} / \mathrm{h} ; 100 \mu \mathrm{l}$ volume, Alzet, Cupertino, CA). Heparin (187 USP U/mg, Sigma, Oakville, ON) was used in a 1:2 (w/w) ratio to bFGF to stabilize and potentiate its activity.

A rat intrathecal catheter (Polyurethane, 0007740, Alzet, Cupertino, CA) composed of three segments with differing diameter was used to delivery GFs and $\mathrm{NgR}$. The catheter was coated with $0.5 \%$ BSA in PBS for 3 $\mathrm{h}$, rinsed with $100 \mu \mathrm{g} / \mathrm{ml}$ rat serum albumin in PBS, and then dried overnight. The ALZET connection $(1.02 \mathrm{~mm}$ OD; $0.61 \mathrm{~mm} \mathrm{ID)} \mathrm{part} \mathrm{of} \mathrm{the} \mathrm{catheter} \mathrm{was} \mathrm{connected}$ to the outlet of the minipump. Following the procedure described by the manufacturer, the osmotic pumps were primed in sterile saline at $37^{\circ} \mathrm{C}$ overnight before implantation to allow immediate pumping of $\mathrm{NgR}$ or GFs.

After spinal fusion, the osmotic pumps were placed into skin pouches on the back of the rats (bilaterally for group 1 with two pumps) and kept in position with sutures. The thinnest segment of the catheter was discarded. The catheters were then immobilized with sutures to the caudal part of the spinal fusion wire and musculature. Then the middle segment of the catheter ( $0.84 \mathrm{~mm}$ OD; $0.36 \mathrm{~mm} \mathrm{ID})$ was inserted into the chitosan channel through a small hole cut in the center of the dorsal surface of the channel at the site of the gap between the two stumps. The tip of the catheter protruded 1-1.5 $\mathrm{mm}$ into the chitosan channel (Fig. 1B). Fibrin glue $(20 \mu \mathrm{l} ; 10 \mu \mathrm{l}$ of fibrinogen and $10 \mu \mathrm{l}$ of thrombin; Aventis Behring, Marburg, Germany) was used via a dual port micropipette to seal the hole in the channel as well as to secure the catheter to the channel.

Fibrin glue $(40 \mu \mathrm{l} ; 20 \mu \mathrm{l}$ of fibrinogen and $20 \mu \mathrm{l}$ of thrombin) was also applied to both rostral and caudal stump-channel interfaces. Then, a synthetic expanded polytetrafluoroethylene membrane (ePTFE; Gore-Tex. Gore, Flagstaff, AZ) was positioned to cover the dorsal aspect of the channel-cord construct. The wound was then closed in layers with 3-0 Vicryl sutures (Johnson \& Johnson, Peterborough, Ontario, Canada) for the paraspinal muscles and Michel clips (Fine Science Tools, North Vancouver, B.C., Canada) for the skin.

After surgery, the rats were kept under a thermostatically regulated heating arc lamp until completely awake. The analgesic buprenorphine $(0.03 \mathrm{mg} / \mathrm{kg})$ was administered subcutaneously immediately after operation and every $8 \mathrm{~h}$ for $72 \mathrm{~h}$ postoperatively. Saline $(5 \mathrm{ml})$ was given subcutaneously immediately after operation, daily for the first 5 days postoperatively, and at later stages if animals showed signs of dehydration. All animals had manual bladder evacuation three times daily. All animals received a daily subcutaneous injection of cyclosporine A $(10 \mathrm{mg} / \mathrm{kg}$, Sandimmune; Novartis, East Hanover, NJ) for the duration of the experiments to prevent graft rejection. Any urinary tract infections were treated with ampicillin (125 mg every $12 \mathrm{~h}$, subcutaneously) for 5 
days (52). The minipumps and catheters were removed 4 weeks after placement through a small incision over the pump.

\section{Functional Assessment}

Functional recovery was analyzed weekly during the 12-week survival period using the Basso, Beattie, Bresnahan (BBB) open field locomotor test (3). BBB scoring was conducted by two observers blinded to the experimental groups. All animals were scored and videotaped for 4 min every week for 12 weeks.

\section{Anterograde Axonal Tracing With Biotin Dextran Amine (BDA)}

To visualize axons from the corticospinal tract (CST), anterograde axonal tracing with BDA was performed 12 weeks after channel implantation following completion of the functional assessment. The axonal tracer techniques and immunohistochemical techniques were based on techniques that we have previously reported $(42,62)$. Four to six animals from each group were randomly selected for BDA injection. Under deep anesthesia with $2 \%$ halothane with $1: 2$ nitrous oxide to oxygen, a craniotomy was performed to expose the sensorimotor cortex bilaterally, and 20\% BDA (MW = 10,000, Molecular Probes Inc., OR) dissolved in 0.01 M PBS was injected at four sites in each sensorimotor cortex with a glass micropipet (Corning PYREX obtained from Macalaster Bicknell Co., NJ) attached to a 26gauge needle (Becton Dickinson \& Co., NJ) and a Picospritzer (General Valve Co., Fairfield, NJ) as previously reported $(43,45,66)$. At each site, $1-2 \mu 1$ of BDA (total 5 $\mu \mathrm{l}$ in each side) was injected within a perimeter defined coronally by bregma at -1 to $-3 \mathrm{~mm}$, and sagittally 2 to $3 \mathrm{~mm}$ lateral to the sagittal suture bilaterally. A needle was lowered through the cortex until the bevel could no longer be seen $(1.7 \mathrm{~mm})$. Then, the skin was closed with 6-0 Vicryl. Animals were allowed to survive for 2 more weeks before sacrifice.

\section{Retrograde Axonal Tracing With Fluoro-Gold (FG)}

Twelve weeks after channel implantation, four animals in each group were randomly selected for retrograde tracing with Fluoro-Gold (FG, Fluorochrome, Denver, CO). Rats were reanesthetized as described above, and the spinal cord at L1 was exposed by laminectomy. After a dorsal durotomy and myelotomy $1 \mathrm{~mm}$ lateral to the midline and $1 \mathrm{~mm}$ in length on both sides of the spinal cord at L1, one small piece of gelatin sponge soaked in $4 \mu \mathrm{l}$ of FG in normal saline (4\% for FG) was inserted completely into the central part of the spinal cord at the myelotomy site. Petroleum jelly (Sherwood Medical, St. Louis, MO) was then placed over the spinal cord and FG pledget. After 7 days, the rats were sacrificed and the tissue was prepared as described below. Brain and spinal cord sections were examined for evidence of retrograde labeling of neuronal cell bodies.

\section{Tissue Preparation}

Animals were sacrificed at the end of the planned period of observation (7 days later if FG was inserted, or 14 days later if BDA was inserted). All animals were perfused with $4 \%$ paraformaldehyde, as described previously (42). A 2-cm length of spinal cord centered on the site of SCT and channel placement was excised, after which the chitosan channel was carefully removed.

In FG-injected rats, brain samples were used for evaluation of retrograde labeling whereas the spinal cords were used for axon counts after preservation in Universal Fixative (UF) for 2 weeks and sectioned as described below. The spinal cords from BDA-injected rats were used for immunohistochemistry of frozen sections and anterograde labeling evaluation. The other spinal cord samples without FG or BDA injection were randomly allocated for paraffin-embedded sections or frozen sections.

The spinal cords for paraffin-embedding were postfixed in $10 \%$ neutral buffered formalin, then embedded in paraffin, after which, $8-\mu \mathrm{m}$-thick parasagittal sections were cut in a 1:9 series and mounted on Superfrosted Plus slides (Fisher Scientific Markham, ON). Every ninth section was stained with luxol fast blue with hematoxylin and eosin (LFB/HE) for general morphology. Each paraffin section of that series was then prepared for immunohistochemistry as described below. The spinal cords for frozen sections were cryoprotected with $30 \%$ sucrose in $0.1 \mathrm{M} \mathrm{PBS}$ at $4^{\circ} \mathrm{C}$, and then frozen and embedded in Frozen Section Medium compound (Stephens Scientific, Riverdale, NJ). Parasagittal sections (20 $\mu \mathrm{m}$ thick) were cut in a 1:9 series on a cryostat and mounted on cold $\left(-20^{\circ} \mathrm{C}\right)$ Superfrosted Plus microscope slides. The brain of animals injected with FG was prepared as described previously (62). The number of neurons retrogradely labeled with FG in the reticular, raphe, vestibular, and red nuclei were counted using a fluorescent microscope (Nikon Eclipse TE300, Nikon, Mississauga, ON) (62). Every alternate brain section was used to determine the number and location of FG-labeled motor neurons. Autofluorescence was distinguished from true tracer labeling by examining sections with all three filters. Images were captured with an Optronics digital camera and the Bioquant Nova Prime for Windows 9x Version 6.50.10 MR.

\section{Immunohistochemistry}

The following monoclonal antibodies were used: mouse anti-neurofilament 200 (NF200; 1:400 dilution in paraffins sections and 1:500 in frozen; Sigma, St. Louis, 
MO) for neurons and axons; mouse anti-glial fibrillary acidic protein (GFAP; 1:200, Chemicon, Temecula, CA) for astrocytes; mouse anti-coiled-coiled protein 1 (CC1; 1;1000, Calbiochem, San Diego, CA) for oligodendrocytes; mouse anti-microtubule-associated protein 2 (MAP2; 1:1000 dilution, Chemicon) for neurons and dendrites; neuronal nuclei (NeuN; 1:100 dilution, Chemicon) for neurons; mouse anti-Ki67 (Ki67; 1:200; clone MM1, Novacastra, Burlington, ON) to visualize proliferating cells. Polyclonal antibodies used were: rat anti-calcitonin gene related peptide (CGRP, 1:3000, Diasorin, Stillwater, MN) for sensory and motor axons from dorsal root ganglia (DRG) and local motor neurons; rabbit anti-green fluorescent protein (GFP; 1:500, Abcam Inc, Cambridge, MA) to visualize GFP. In all the immunohistochemistry procedures, appropriate negative controls were used with the omission of the primary antibodies.

Immunohistochemistry of Paraffin-Fixed Tissue. For immunohistochemistry of paraffin-embedded sections, anti-GFP, NF200, GFAP, and CGRP antibodies were used. The immunohistochemistry was performed as described previously (42). The sections were observed under a Leica DMRB light microscope (Nussloch, Germany) and photographed using an image tiling and stitching system (Stereo Investigator Software, version 6, MicroBrightField, Inc., Williston, VT).

Immunohistochemistry of Frozen Tissue and Visualization of BDA. For immunohistochemistry of frozen sections and visualization of BDA, anti-NF200, GFAP, CC1, MAP2, and Ki67 antibodies were used. The immunohistochemistry was performed as previously reported $(38,39,42,44)$. The sections were counterstained with the nuclear dye DAPI mounting medium (Vector Laboratories, Burlington, ON, Canada) and coverslipped. Every ninth slide in a series of frozen sections was selected for BDA detection. Segments of the cervical and upper thoracic spinal cord were sectioned transversely in a cryostat at $20 \mu \mathrm{m}$ for BDA detection. The BDA procedure was performed as described previously (61). All sections were examined and photographed using a ZeissLSM 510 confocal microscope (Zeiss, Oberkochen, Germany). Z-stack images were accumulated based on 20-30 optical sections, at $0.5 \mu \mathrm{m}$ in thickness per section. Then, the entire thickness of the section was visualized using the Image J software system. Threedimensional (3D) imaging was constructed using Imaris software (Bitplane, Exton, PA).

\section{Stereological Cell Counts of GFP-Positive Cells}

Every ninth equidistant frozen section of spinal cord was selected from each animal and counterstained with the nuclear dye DAPI. The spinal cords were viewed with a Leica DMRB light microscope at $100 \times$ objective magnification, and the cell counts were performed using Stereo Investigator Software $(42,71)$. The entire section of the spinal cord was divided by the sampling grid into $800 \times 800-\mu \mathrm{m}$ segments and the counting frame area was maintained at $30 \times 30 \mu \mathrm{m}$ and $15 \mu \mathrm{m}$ in thickness. GFP-positive cells and their nuclei were observed under a green or blue filter, respectively, and only GFP-positive cells containing DAPI-positive nuclei were counted as GFP-positive NSPCs. There was some autofluorescence in the spinal cord tissues after SCT visualized under a red filter, as previously reported (62), and therefore we also analyzed the GFP-positive cells containing DAPI-labeled nuclei under a red filter and found no GFP-positive cells containing DAPI-labeled nuclei.

\section{Stereological Analysis of Differentiation of NSPCs}

Five frozen spinal cord sections containing the midpoint of the tissue bridge in the channels in the NSPCcontaining groups were selected for each antibody, including anti-GFAP, CC1, or MAP2, for astrocytes, oligodendrocytes, and neurons, respectively, and immunostained and counterstained with DAPI as described above (42). Each immunostained section was observed and counts made as described above. First, GFP-positive cells containing DAPI-labeled nuclei were counted under the green and blue filters as GFP-positive NSPCs, and then these cells were also observed under a red filter and counted as differentiated cells when they were also positive for each antibody. The percentage of differentiated NSPCs was calculated relative to the total number of GFP-positive NSPCs.

\section{Axon Counts and Myelin Measurements in the Tissue Bridge Determined in Thin Sections}

Twelve weeks after channel implantation, three animals in group 1 and four animals in each of groups 2, $3,4,5$, and 6 were randomly chosen for axon counts. After removing the channels, the spinal cord tissues were preserved in universal fixative; a 2-mm segment of spinal cord from the thinnest part of the bridge was removed and then processed as routine EM. Sections (1 $\mu \mathrm{m}$ thick) were then cut and stained with toluidine blue, and examined under the Leica DMRB light microscope $(22,42)$.

The parameters measured include: () fiber diameter (entire myelinated axon diameter) and area (entire myelinated fiber area) with fiber defined as the combination of axon and myelin sheath; 2) axon (inner portion of the fiber not stained with toluidine blue) diameter and area; and 3) the thinnest bridge area. From parameters 1) and 2), the myelin thickness and area were calculated. G-ratio (ratio of axon to entire fibre diameter) and the ratio of axon to myelin area were also calculated. 
These measurements were made on the toluidine blue-stained spinal cord sections. Seven images of highpower fields (HPFs; 5,786 $\mu^{2}$ at a magnification of $1,000 \times$ ) taken randomly without overlap were used and fibers greater than $0.2 \mu \mathrm{m}^{2}$ in area were selected for analysis. Each HPF picture was analyzed with the aid of Image Pro-Plus software (Media Cybernetics, Silver Spring, MD) with customized macroscripts to select and differentiate the color intensity between blue stain and white background with automatic measurements and calculation of the defined parameters. The thinnest bridge area was measured on an image at magnification of $12.5 \times$, and with the software mentioned above the whole area was measured. For sections with moderate to severe cavitations, each cavity was also measured separately and subtracted from the whole section area to yield the area of actual tissue. To calculate the total number of myelinated fibers, images of the thinnest bridge section were taken at magnification of $40 \times$, and the total myelinated fibers number manually counted with the Scion Image program (Scion, Frederick, MD). Utilizing the measured area of thinnest bridge, the density of axons $/ \mathrm{mm}^{2}$ was calculated.

\section{Transmission Electron Microscopy (TEM)}

Five animals were randomly selected for transmission electron microscopy (TEM). Twelve weeks after channel implantation, animals were sacrificed by intraperitoneal injection of sodium pentobarbital and transcardially perfused using $2 \%$ paraformaldehyde with $2.5 \%$ glutaraldehyde in $0.1 \mathrm{M}$ sodium phosphate buffer. The implanted channel was removed, and the tissue bridge was transected at the midpoint encompassing the narrowest part of the bridge. The tissue inside the channel was postfixed in $1 \%$ osmium tetroxide. TEM sections were made as previously reported (2) and then viewed and photographed with a Hitachi H7000 transmission electron microscope (Tokyo, Japan).

\section{Serum Titer of Anti-NgR Antibody}

Four and 12 weeks postsurgery, serum samples from the NgR-treated groups and non-NgR-treated groups were collected to monitor the serum titer of anti-NgR antibodies with ELISA. Rat Nogo-66 receptor protein $(0.5 \mu \mathrm{g} /$ well $)$ or control protein was immobilized in a 96-well Maxisorb ELISA plate (Nunc). After blocking nonspecific binding sites, $50 \mu \mathrm{l}$ of serum samples (various dilutions in PBS) was added in triplicate and incubated at $25^{\circ} \mathrm{C}$ for $2 \mathrm{~h}$. After washing, HRP-conjugated goat anti-rat secondary antibody (Jackson Lab, 1:1000, $50 \mu \mathrm{l} /$ well) was added to each well and incubated for $1 \mathrm{~h}$ at $25^{\circ} \mathrm{C}$. Unbound antibody was removed by three washings and color was developed using the TMB reagent (Pierce) and analyzed in a Plate reader. The measurements were performed and analyzed by Dr. Daniel Lee's group in Biogen Idec Inc. (Cambridge, MA).

\section{Statistical Analysis}

Data from more than two groups was analyzed by oneway analysis of variance (ANOVA), followed by pairwise multiple comparisons using the Bonferroni method. The difference between two groups was analyzed by $t$-test. Statistical analysis was performed using Sigma Plot 8.0 for Windows and Microsoft ${ }^{\circledR}$ Excel 2000. All behavioral and histological evaluations were performed blindly without knowledge of the treatment group.

\section{RESULTS}

\section{Extramedullary Chitosan Channel Implantation in Combination With Growth Factors Produced Excellent Long-Term Survival of NSPCs After SCT}

There was excellent survival of NSPCs in all four groups employing laminin-coated chitosan channels, either with growth factor (GF) or NgR or their combination (groups 1-3 and 7, Table 1). LFB/HE-stained paraffin sections showed that there was a tissue bridge in all four groups. In general, the bridges consisted of a central portion between the cord stumps and a lateral portion, situated lateral to the central bridge and extending rostral and caudal along the subarachnoid surface of the stumps within the channels (Fig. 2A), consistent with our previous study (42).

Fluorescent microscopy of frozen sections showed that numerous GFP-positive NSPCs were seen both in the lateral and central bridges in the channels (Fig. 2B, C). The GFP-positive NSPCs also invaded into the white and gray matter of the cord stumps within the channels (Fig. 2B, E-H). Interestingly, in many cases, the NSPCs migrated out of the ends of the channels and also emerged through the hole in the channels made for catheter insertion (Fig. 2B, D).

Stereological cell counts of the GFP cells showed that at 14 weeks posttransplantation, group 1 had $2.89 \times$ $10^{6}$ cells, group 2 had $2.78 \times 10^{6}$ cells, groups 3 had $1.29 \times 10^{6}$ cells, and group 7 had $1.10 \times 10^{6}$ cells, respectively (Table 2 ). GF-treated groups showed significantly improved long-term survival of NSPCs compared to the non-GF-treated groups (i.e., group 1 vs. 3 and group 2 vs. 7; $p$ <.01) (Table 2). However, NgR had no effect on the survival of NSPCs based on the comparison between $\mathrm{NgR}$-treated groups with the non$\mathrm{NgR}$-treated groups (i.e., group 1 vs. 2 and group 3 vs. $7 ; p>0.05$ ) (Table 2).

Ki67, a cell proliferation marker, was used to examine the proliferation of the transplanted cells 14 weeks after transplantation. None of the GFP-positive cells were labeled with Ki67, indicating that there was no continuing cell proliferation within this population. 

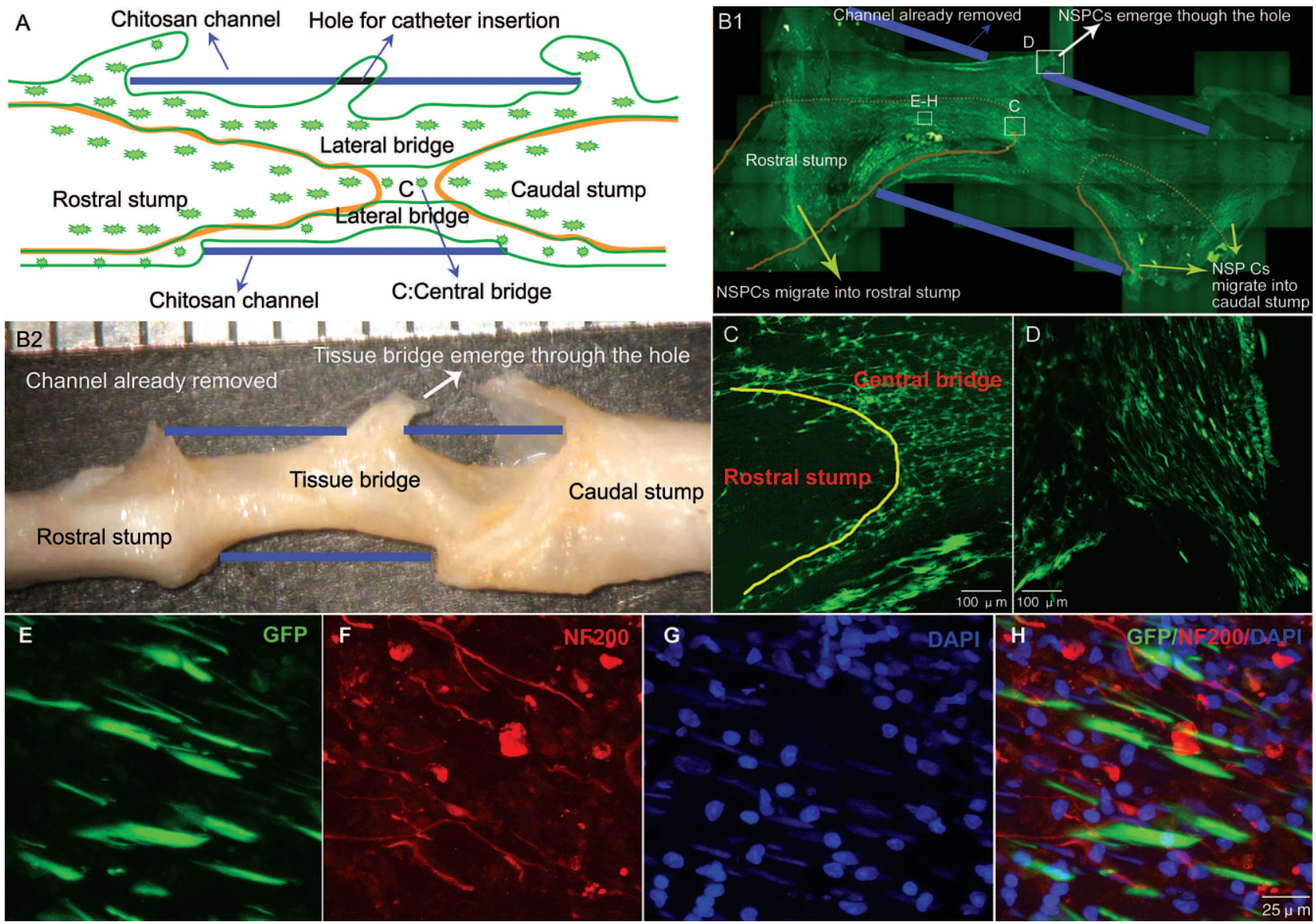

Figure 2. NSPCs survived well in the implanted chitosan channels. Parasagittal frozen sections 14 weeks after channel implantation in croup 1 channel $+\mathrm{NSPCs}+\mathrm{NgR}+\mathrm{GF}$. (A) Schematic drawing of the tissue bridge in the channel showing the central and lateral tissue bridges in the channel and the location of the catheter hole. (B) Macroscopic appearance from the lateral aspect and the corresponding histological section showing a large tissue bridge and the location of the channel. The orange lines outline the rostral and caudal stumps of the spinal cord. The blue lines indicate the approximate location of the walls of the channel that was removed prior to sectioning. Many GFP-positive NSPCs were seen in both the lateral and central bridges in the channels. A higher magnification image is shown in (C). Many GFP-positive NSPCs invade and occupy the stump (green arrows in B) and emerge through the hole in the channel used for catheter insertion (white arrow in B and higher magnification images are shown in D). (C) Confocal laser scanning Z-stack images corresponding to the boxed area in (B) shows numerous GFP-positive NSPCs in the central bridges. GFP signal is in green and the rostral stump is outlined in orange $(10 \times)$. (D) Confocal laser scanning Z-stack images corresponding to the boxed area in (B) shows numerous GFP-positive NSPCs emerged through the hole in the channel used for catheter insertion $(10 \times)$. (E-H) Confocal laser scanning Z-stack images corresponding to the boxed area in (B) show numerous GFP-positive NSPCs that have invaded the rostral stump: GFP signal is in green, NF200 signal is in red, and DAPI signal is in blue. Colocalized signals with green and red or blue are in yellow or azure, respectively. Transplanted GFP-positive cells in the rostral stump are linearly related to the host NF200-positive axons, but the signals do not overlap. Scale bars: $1 \mathrm{~mm}(\mathrm{~B}) ; 100 \mu \mathrm{m}(\mathrm{C}, \mathrm{D}) ; 25 \mu \mathrm{m}(\mathrm{E}-\mathrm{H})$.

Although there were no signs of tumorigenesis macroscopically or microscopically, several animals had large masses of GFP-positive cells in the bridges, both centrally and laterally, and some animals had a large mass of cells at the ends of the bridges (Fig. 3A-E).

\section{Differentiation of NSPCs}

Immunohistochemistry showed that GFP-positive cells colocalized with CC1-positive oligodendrocytes (Fig. 4A, B) or GFAP-positive astrocytes (Fig. 4C) in the four groups (groups 1-3 and 7), either with GF or $\mathrm{NgR}$ alone or in combination. Some GFP-positive cells expressing CC1 had a close relationship to NF200-positive axons, possibly indicating myelination of axons by NSPC derived oligodendrocytes.

Stereological cell counts at 14 weeks posttransplantation showed that $29.41 \%$ of the transplanted NSPCs differentiated into oligodendrocytes in group $1,27.77 \%$ in group 2, $13.86 \%$ in group 3, and $12.99 \%$ in group 7 , respectively (Table 2). At 14 weeks, $10.74 \%$ of the 
Table 2. Effect of Growth Factors Combination and NgR on the Long-Term Survival and Differentiation of NSPCs

\begin{tabular}{lccr}
\hline Groups & No. of Surviving NSPCs & Oligodendrocytes (\%) & Astrocytes $(\%)$ \\
\hline 1. Channel + NSPCs + GF + NgR & $2,888,105 \pm 95,707$ & $29 \pm 8$ & $11 \pm 4$ \\
2. Channel + NSPCs + GF & $2,781,650 \pm 105,926$ & $28 \pm 8$ & $19 \pm 8$ \\
3. Channel + NSPCs + NgR & $1,290,665 \pm 309,082$ & $14 \pm 13$ & $8 \pm 4$ \\
7. Channel + NSPCs & $1,100,798 \pm 243,200$ & $13 \pm 5$ & $13 \pm 3$ \\
Groups compared by $t$-test + Bonferroni correction & & & + \\
A: 1 versus 3 GF & ++ & ++ & 0 \\
B: 2 versus 7 GF & ++ & 0 & - \\
C: 1 versus 2 NgR & 0 & 0 & -- \\
D: 3 versus 7 NgR & 0 & + & - \\
\hline
\end{tabular}

Values are mean $\pm \mathrm{SD}(n=3$ in each group). Significant increase: $+p<0.05,++p<0.01$. No significant difference $(0): p>0.05$. Significant decrease: $-p<0.05,-p<0.01$. Growth factors significantly improve the long-term survival of NSPCs when comparing the GF-treated groups with the non-GF-treated groups [i.e., group 1 vs. 3 and group 2 vs. $7(p<0.01)]$. NgR has no effect on the survival of NSPCs when comparing the NgR-treated groups with the non-NgR-treated groups [i.e., group 1 vs. 2 and group 3 vs. $7(p>0.05)$ ]. Growth factors significantly induced increased differentiation of NSPCs into oligodendrocytes especially and also astrocytes when comparing the GF-treated groups with the non-GF-treated groups [i.e., group 1 vs. 3 and group 2 vs. 7 for oligodendrocytes $(p<0.01)$ and group 2 vs. 7 for astrocytes $(p<0.05)]$. However, NgR significantly decreased the astrocytic differentiation of NSPCs but did not significantly alter the phenotypic distribution of oligodendrocytes when comparing the $\mathrm{NgR}$-treated groups with the non-NgR-treated groups [i.e., group 1 vs. $2(p<0.05)$ and group 3 vs. $7(p<0.01)$ for astrocytes, and group 1 vs. 2 and group 3 vs. 7 for oligodendrocytes $(p>0.05)]$.
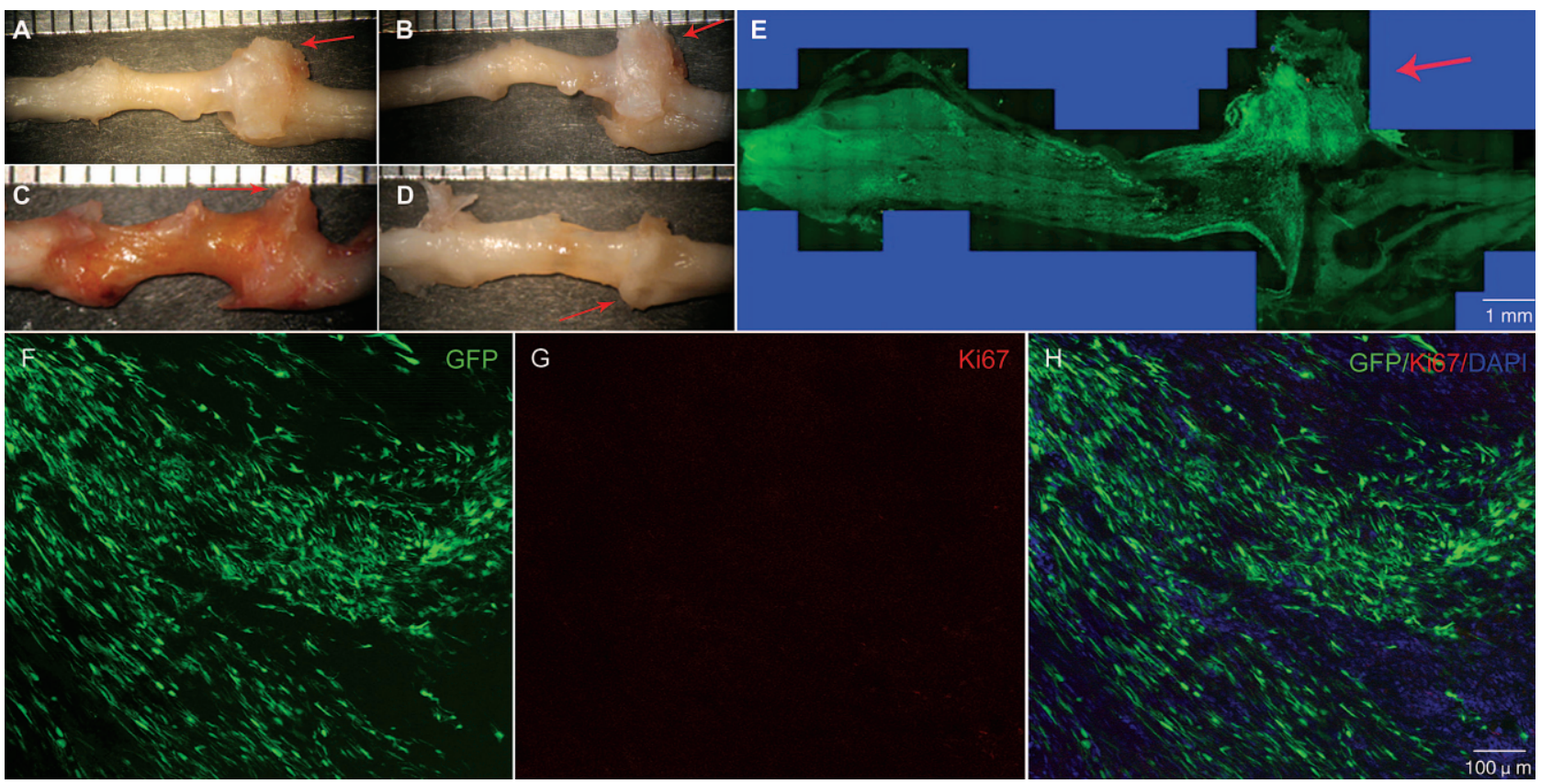

Figure 3. No excess cell proliferation or tumor formation at 14 weeks after implantation. (A-D) Macroscopic and (E) confocal microscopical images showed that there were no signs of tumorigenesis of the transplanted NSPCs along the spinal cords at 14 weeks posttransplantation, although several animals had large numbers of GFP-positive cells in the bridges, both centrally and laterally (F). (A-E) The red arrows point to masses of GFP-positive cells. (F-H) Confocal laser scanning Z-stack images showed that none of the GFP-positive cells was labeled with Ki67, a cell proliferation marker, indicating that these donor cells were not proliferating at 14 weeks posttransplantation. GFP signal is in green, Ki67 signal is in red, and DAPI signal is in blue. No overlap was seen for transplanted GFP-positive cells with Ki67. Scale bars: $1 \mathrm{~mm}(\mathrm{E}) ; 100 \mu \mathrm{m}(\mathrm{F}-\mathrm{H})$. 


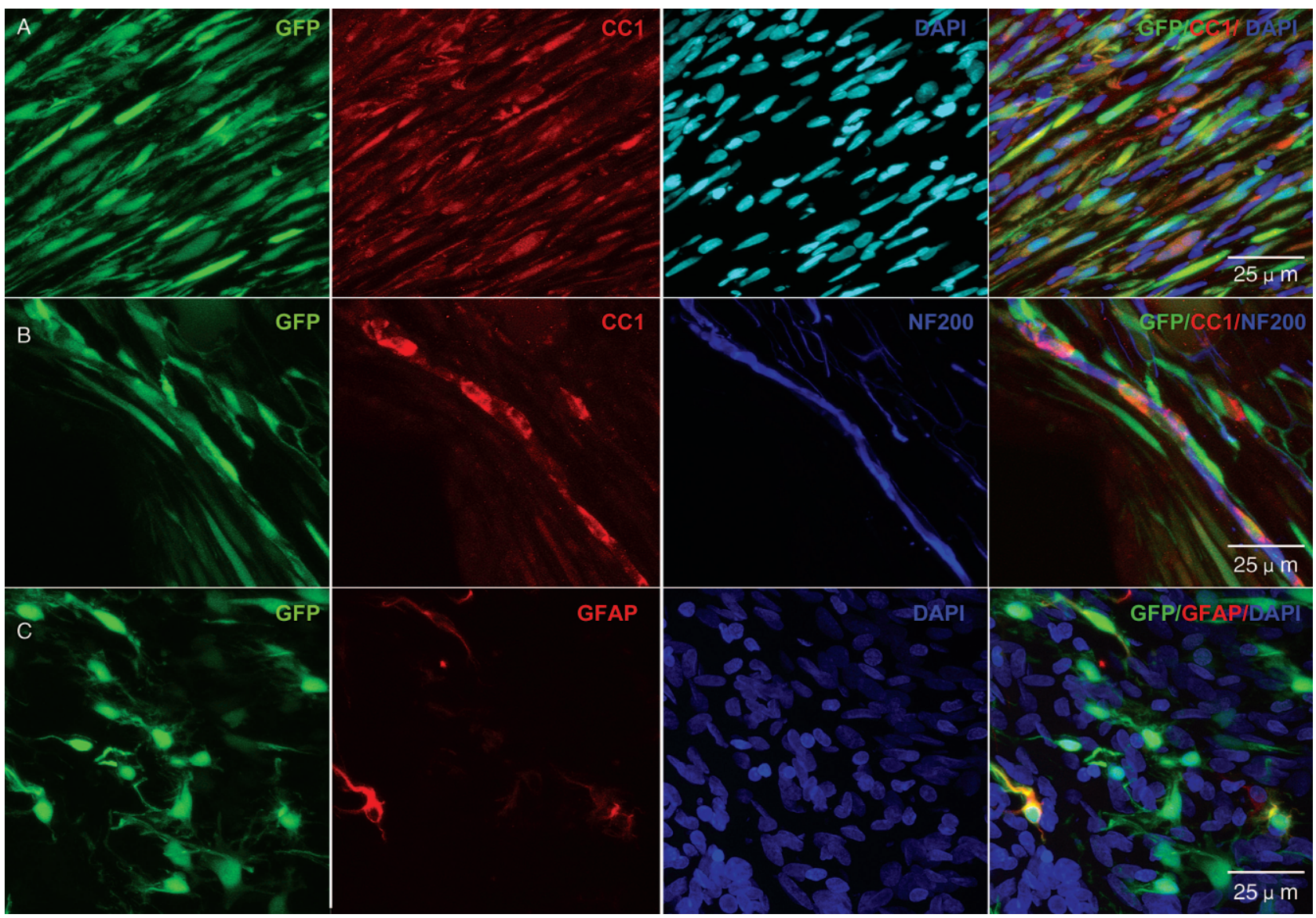

Figure 4. NSPCs differentiated mainly into oligodendrocytes and astrocytes. Confocal laser scanning Z-stack images composed of 20-30 confocal micrographs of $0.5 \mu \mathrm{m}$ thickness per section in the bridges 14 weeks after channel implantation. GFP signal is in green $(\mathrm{A}-\mathrm{C})$ and $\mathrm{CC} 1$ or GFAP are in red (A and $\mathrm{B}$ for $\mathrm{CC} 1$, and $\mathrm{C}$ for GFAP, respectively), and DAPI or NF200 signal is in blue (A, C for DAPI; B for NF200). Colocalized signals with green and red or blue are in yellow or azure, respectively. There are many GFP-positive cells in the tissue bridge. Some GFP-positive cells colocalize with CC1 (A, B) or GFAP (C) corresponding to oligodendrocytes or astrocytes, respectively. Some GFP-positive cells colocalize with CC1-positive cells and had a close relationship to NF200 positive axons, likely indicating myelination of axons (B). Scale bars: $25 \mu \mathrm{m}$.

transplanted NSPCs differentiated into astrocytes in group $1,18.74 \%$ in group $2,7.53 \%$ in group 3, and $12.45 \%$ in group 7 , respectively (Table 2).

Comparison of the GF-treated groups with the nonGF-treated groups showed that GF significantly increased differentiation of NSPCs into oligodendrocytes and also astrocytes (to a lesser extent): group 1 versus 3 and group 2 versus 7 for oligodendrocytes $(p<0.01)$ and group 2 versus 7 for astrocytes $(p<0.05)$. Additionally, NgR significantly decreased the astrocytic differentiation of NSPCs but did not alter the phenotypic distribution of oligodendrocytes: group 1 versus $2(p<$ $0.05)$ and group 3 versus $7(p<0.01)$ for astrocytes, group 1 versus 2 and group 3 versus 7 for oligodendrocytes $(p>$ 0.05). No neurons were seen in any of these groups.

\section{Axonal Regeneration}

Fluorescent microscopy showed large numbers of NF200-positive axons not only in the central bridges but also in the lateral bridges in the $\mathrm{NgR}$ treated groups (groups 1, 3, and 5). These regenerated axons were often parallel to the channel wall, and some even migrated through the catheter hole in the channel (Fig. 5). Many GFP-positive cells were linearly aligned and closely related to the axons, and at times they appeared to wrap around the axons as identified by merged and split Zstack confocal photograph (Fig. 6), resulting in a partial overlap, but there was no complete colocalization between the NF200- and GFP-positive cells.

$\mathrm{NgR}$ promoted axonal sprouting/regeneration and myelination. $\mathrm{NgR}$ alone (group 5) produced a significant increase in the total number of myelinated fibers $(p<$ $0.05)$, axon density $(p<0.01)$, bridge area $(p<0.01)$, myelin thickness and area in the bridges $(p<0.05)$ compared with group 6 (channel only) (Table 3, comparison A). $\mathrm{NgR}$ alone (group 5) produced a total of 3,000 \pm 854.7 myelinated fibers, whereas only $622 \pm 286.3$ were present in the empty-channel group 6 . The effect of $\mathrm{NgR}$ 


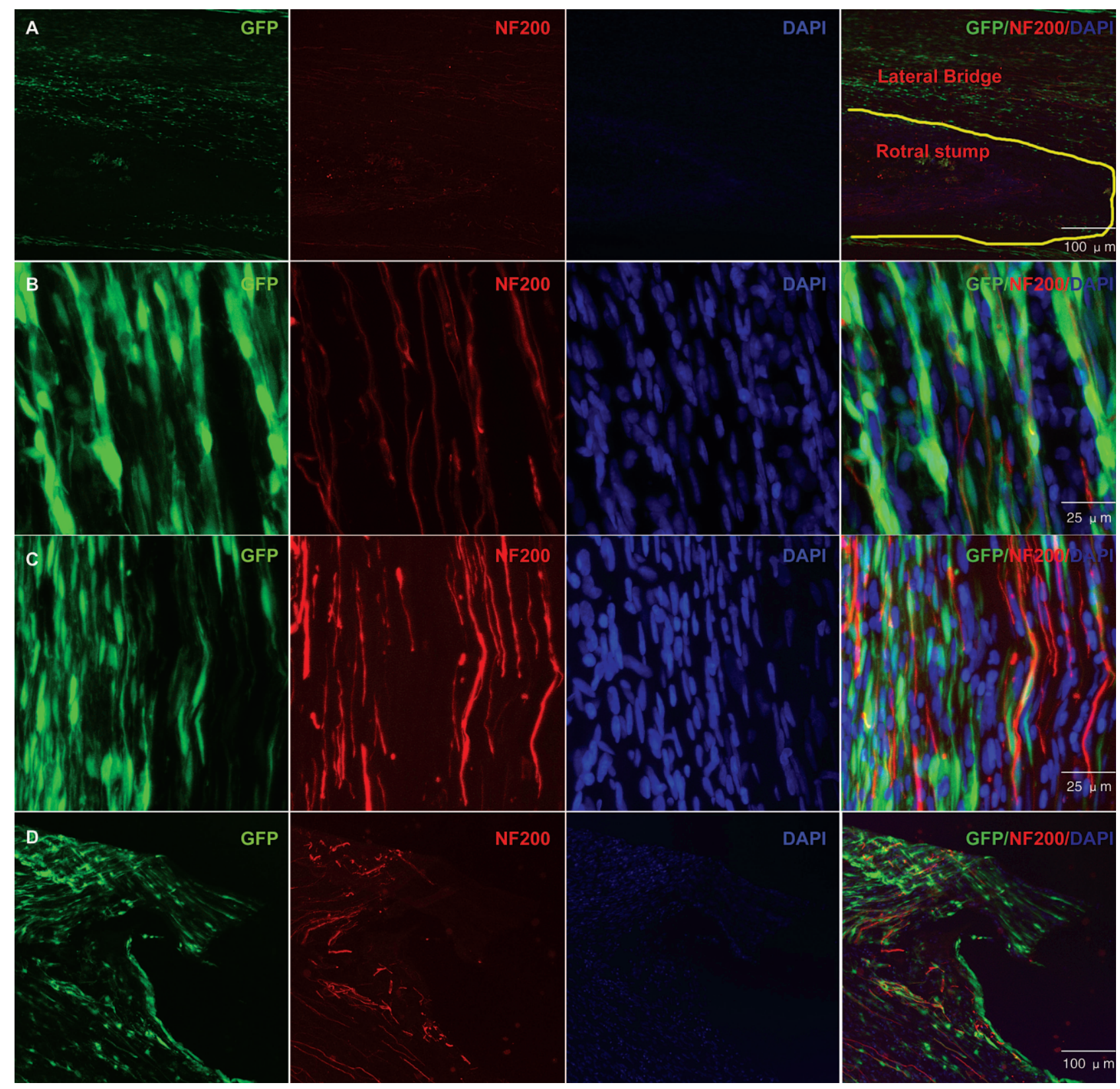

Figure 5. Axonal regeneration. Large numbers of NF200-positive axons were present in the lateral and central bridges. The regenerated axons were often parallel to the channel wall. (A) Confocal laser scanning images (10×) shows numerous NF200positive axons and surviving GFP-positive NSPCs in the lateral bridges. A few GFP-positive NSPCs were also seen invading the rostral stump. NF200 signal is in red, GFP signal is in green, and DAPI signal is in blue. Colocalized signals with green and red or blue are in yellow or azure, respectively. The rostral stump is outlined with a yellow line. (B-D) Confocal laser scanning Zstack images $(63 \times)$ showed that there were large numbers of NF200-positive axons regenerated and excellent transplanted NSPCs survived in the central bridge (B), lateral bridges (C), and even migrated through the hole in the channel used for catheter insertion (D). The transplanted GFP-positive cells were aligned linearly and closely related to the regenerated NF200-positive axons. Scale bars: $100 \mu \mathrm{m}(\mathrm{A}, \mathrm{S}) ; 25 \mu \mathrm{m}(\mathrm{B}, \mathrm{C})$.

on promoting axonal regeneration and myelination was further confirmed in that the NgR-treated group 5 had greater total myelinated fiber number $(p<0.01)$, axon density $(p<0.01)$, and myelin area $(p<0.01)$ than the
GF-treated group 4 (Table 3, comparison B). The combination of $\mathrm{NgR}$ with NSPCs (group 3) also significantly enhanced axonal sprouting/regeneration (total myelinated fibers number is 2,285 $\pm 1,727.8, p<0.05)$ and 


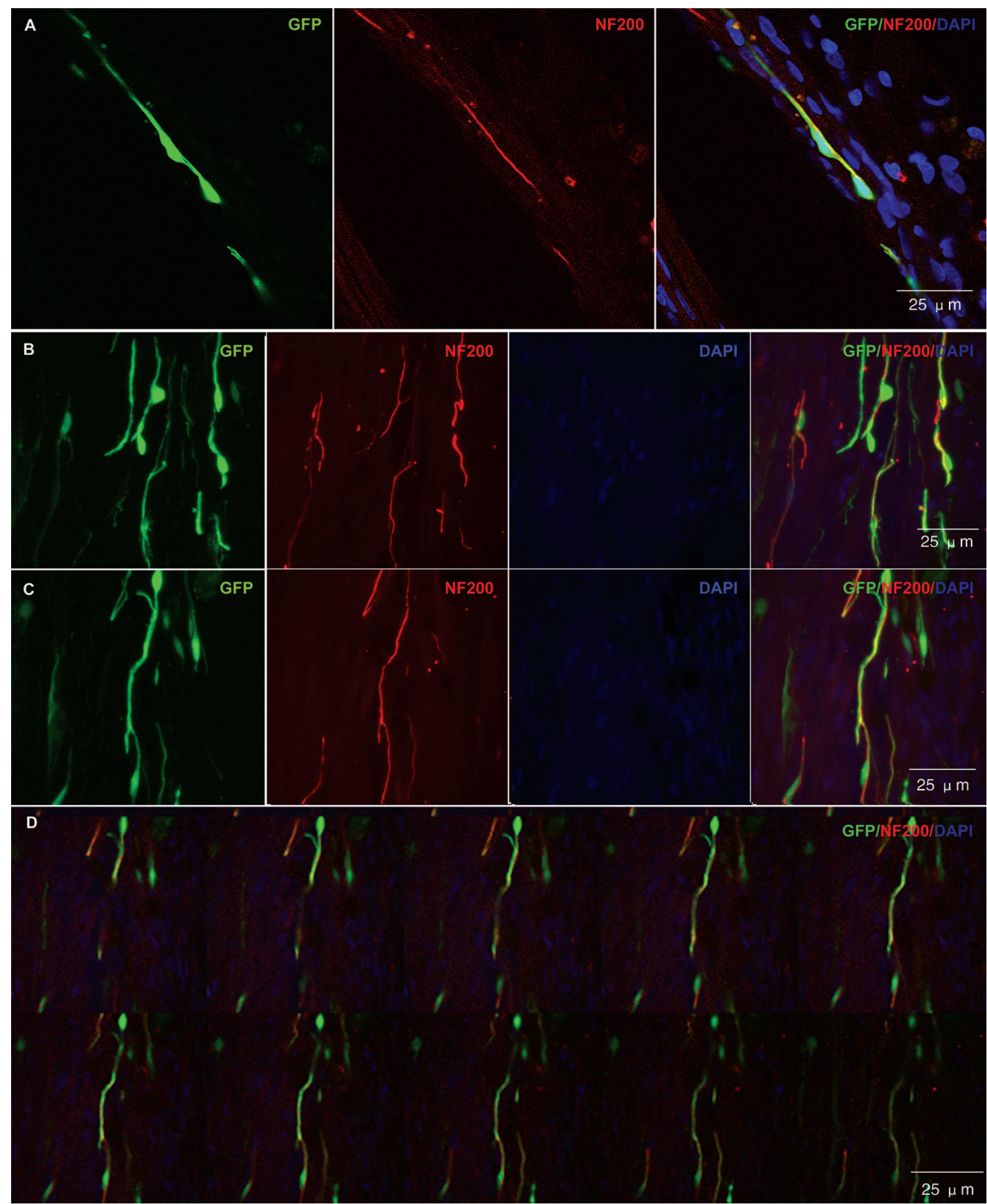

Figure 6. The regenerated axons had a definite relationship adjacent to NSPCs. Many GFP-positive cells were aligned linearly and closely related to the axons, and at times they appeared to wrap around the axons as identified by merged (A-C) and split Z-stack confocal microscopy (D, split Z stack confocal photograph from $\mathrm{C}$ ), resulting in a partial overlap, but there was no complete colocalization between the NF200- and GFP-positive cells. Scale bars: $25 \mu \mathrm{m}$. 
Table 3. Axon Counts

\begin{tabular}{|c|c|c|c|c|c|c|c|}
\hline \multirow[b]{2}{*}{ Groups } & \multirow{2}{*}{$\begin{array}{c}\text { Total } \\
\text { Myelinated } \\
\text { Fibers } \\
(N)\end{array}$} & \multirow{2}{*}{$\begin{array}{c}\text { Thinnest } \\
\text { Bridge Area } \\
\left(\mathrm{mm}^{2}\right)\end{array}$} & \multirow{2}{*}{$\begin{array}{l}\text { Axon Density } \\
\qquad\left(N / \mathrm{mm}^{2}\right)\end{array}$} & \multicolumn{2}{|c|}{$\begin{array}{l}\text { Myelinated Fiber } \\
\text { (Axon + Myelin) }\end{array}$} & \multicolumn{2}{|c|}{ Myelin } \\
\hline & & & & Diameter & Area & Thick & Area \\
\hline 1. Channel + NSPCs $+\mathrm{GF}+\mathrm{NgR}(n=3)$ & $1,479 \pm 1,638$ & $1.9 \pm 0.5$ & $673 \pm 629$ & $3.56 \pm 0.6$ & $8.13 \pm 2.9$ & $0.9 \pm 0.2$ & $5.3 \pm 2.6$ \\
\hline 2. Channel + NSPCs + GF $(n=3)$ & $1,154 \pm 262$ & $2.8 \pm 0.3$ & $387 \pm 107$ & $3.65 \pm 0.4$ & $7.93 \pm 2.0$ & $0.9 \pm 0.1$ & $4.4 \pm 1.4$ \\
\hline 3. Channel + NSPCs $+\operatorname{NgR}(n=3)$ & $2,285 \pm 1,728$ & $2.4 \pm 0.7$ & $1,012 \pm 843$ & $3.86 \pm 0.3$ & $9.11 \pm 1.8$ & $0.9 \pm 0.1$ & $5.1 \pm 1.7$ \\
\hline 4. Channel + GF $(n=4)$ & $861 \pm 707$ & $2.6 \pm 1.4$ & $456 \pm 359$ & $4.33 \pm 0.5$ & $10.25 \pm 2.2$ & $0.9 \pm 0.2$ & $6.5 \pm 1.4$ \\
\hline 5 Channel + NgR $(n=4)$ & $3,000 \pm 855$ & $2.1 \pm 0.7$ & $1,629 \pm 1,001$ & $4.01 \pm 0.4$ & $10.90 \pm 2.3$ & $1.1 \pm 0.1$ & $6.9 \pm 1.9$ \\
\hline 6. Channel $(n=3)$ & $622 \pm 286$ & $1.2 \pm 0.6$ & $537 \pm 207$ & $3.99 \pm 0.2$ & $9.14 \pm 1.2$ & $0.9 \pm 0.1$ & $4.4 \pm 1.9$ \\
\hline \multicolumn{8}{|l|}{$\begin{array}{l}\text { Groups compared by } t \text {-test }+ \text { Bonferroni } \\
\text { correction }\end{array}$} \\
\hline A: 5 versus $6 \mathrm{NgR}$ & + & ++ & ++ & 0 & + & + & ++ \\
\hline B: 5 versus $4 \mathrm{NgR}$ versus GF & $++\mathrm{NgR}$ & 0 & $++\mathrm{NgR}$ & 0 & 0 & 0 & $++\mathrm{NgR}$ \\
\hline C: 3 versus $6 \mathrm{NSPC}+\mathrm{NgR}$ & + & ++ & 0 & 0 & 0 & 0 & 0 \\
\hline D: 4 versus $6 \mathrm{GF}$ & 0 & + & 0 & + & 0 & 0 & 0 \\
\hline E: 2 versus 6 NSPC + GF & ++ & ++ & 0 & 0 & 0 & 0 & 0 \\
\hline F: 1 versus $6 \mathrm{NSPC}+\mathrm{GF}+\mathrm{NgR}$ & 0 & + & 0 & 0 & 0 & 0 & 0 \\
\hline
\end{tabular}

Values are mean \pm SD. Significant increase: $+p<0.05 ;++p<0.01$. No significant difference $(0): p>0.05$. NgR alone promotes axonal sprouting/ regeneration and myelination. $\mathrm{NgR}$ alone (group 5) produced a significant increase in the total myelinated fibers number $(p<0.05)$, axon density $(p<0.01)$, bridge area $(p<0.01)$, myelin thickness, and area in the bridges $(p<0.05)$ compared with group 6 (comparison A). The effect of $\mathrm{NgR}$ on promoting axonal regeneration and myelination was further confirmed in that the NgR-treated group 5 had greater total myelinated fibers number $(p<0.01)$, axon density $(p<0.01)$, and myelin area $(p<0.01)$ than GF-treated group 4 (comparison B). The combination of NgR with NSPCs can also significantly enhance total myelinated fibers number $(p<0.05)$ and bridge area $(p<0.01)$ (comparison C). GFs alone had no effect on axonal sprouting/regeneration. There was no significant difference between group 4 and group 6 in either total myelinated fiber number or axon density $(p>0.05)$ (comparison D). Compared with group 6, the combination of NSPCs with both NgR and GFs significantly increased the bridge area $(p<0.05)$. However, it had no effect on total myelinated fibers numbers (comparison $\mathrm{F}$ ).

bridge area $(p<0.01)$ compared with group 6 (Table 3 , comparison $\mathrm{C}$ ).

In contrast, GFs alone had no effect on axonal sprouting/regeneration. There was no significant difference between group 4 (Channel + GF) and group 6 (channel only) in either total myelinated fiber number or axon density $(p>0.05)$ (Table 3, comparison D). However, we did not do axon counts on group 7 (Channel + NSPCs), there is no direct comparison between groups 6 and 7. Thus, it is impossible to assess the effect of NSPCs alone on axonal sprouting/regeneration in this study.

The combination of NgR, GFs, and NSPCs had a synergetic effect on bridge formation, but not axonal sprouting/regeneration. Compared with group 6 (channel only), NgR alone (Table 3, comparison A), GFs alone (Table 3, comparison D), the combination of NSPCs with either NgR (Table 3, comparison C), or GFs (Table 3, comparison E), and the combination of NSPCs with both NgR and GFs (Table 3, comparison F) all significantly increased the bridge area. However, the combination of all three had no effect on total number of myelinated fibers (Table 3, comparison F).

The diameter of the regenerated axons in the channels was variable. Most of the regenerated fibers (axon + myelin) in all groups were between 3.6 and $4.3 \mu \mathrm{m}$ in diameter (Table 3). Many CGRP-positive sensory axons were also found in the bridge colocalized with GFPpositive cells (data not shown).

A small number of descending corticospinal tract axons grew into the central bridges as shown by anterograde tracing with BDA. Linear BDA-positive structures in parasagittal sections were considered to be axons. In all groups, BDA-labeled fibers were detected in the rostral stump of the spinal cord, but there were no BDAlabeled fibers in the caudal stump in any rats. However, there were a small number of BDA-positive axons in the central bridge in the NSPCs containing groups: one of six rats in group 1, three of five rats in group 2, and two of six rats in group 3 (Fig. 7). There were too few BDAlabeled fibers for accurate quantitation.

To further characterize the origin of axons that regenerated in the channels, retrograde axonal tracing with FG placed at T13-L1 was performed in four rats per group from groups 1-6 at 12 weeks. There were no retrogradely labeled cells in any brain stem nuclei, and thus there was no reticulospinal, raphespinal, vestibulospinal, or rubrospinal axonal regeneration.

TEM analysis showed that oligodendrocytes and Schwann cells contributed to the myelination of regenerated axons in NgR-treated groups. Twelve weeks after 
channel implantation, TEM of the thinnest part of the central tissue bridge confirmed excellent axonal regeneration and myelination in NgR-treated groups (Fig. 8). Regenerating axons were found in the lateral and central bridges. There were large numbers of regenerated axons of variable diameter and myelination (Fig. 8A, D). Both oligodendrocytes (Fig. 8A-C) and Schwann cells (Fig. $8 \mathrm{D}$, E) contributed to the myelination. Schwann cells were identified by their basal lamina and their one-toone relationship to myelinated axons (Fig. 8D, E). Myelinating cells without a basal lamina were also observed, and these had the morphological features of oligodendroglial cells, and generally contained more than one axon (Fig. 8A-C). There were also many nonmyelinated axons in the bridges. We also observed large numbers of fibroblast-like cells and collagen in the lateral bridges of all groups. Fewer axons were seen in non-NgR-treated groups.

\section{Low Serum Anti-NgR Antibody Titers Were Detected 4 and 12 Weeks After NgR Administration, Indicating Little Immune Response to This Protein}

Four and 12 weeks postsurgery, serum samples from the $\mathrm{NgR}$-treated groups and non-NgR-treated groups were collected to assess the level of anti-NgR antibody with ELISA. The sera titers in the NgR-treated groups

A
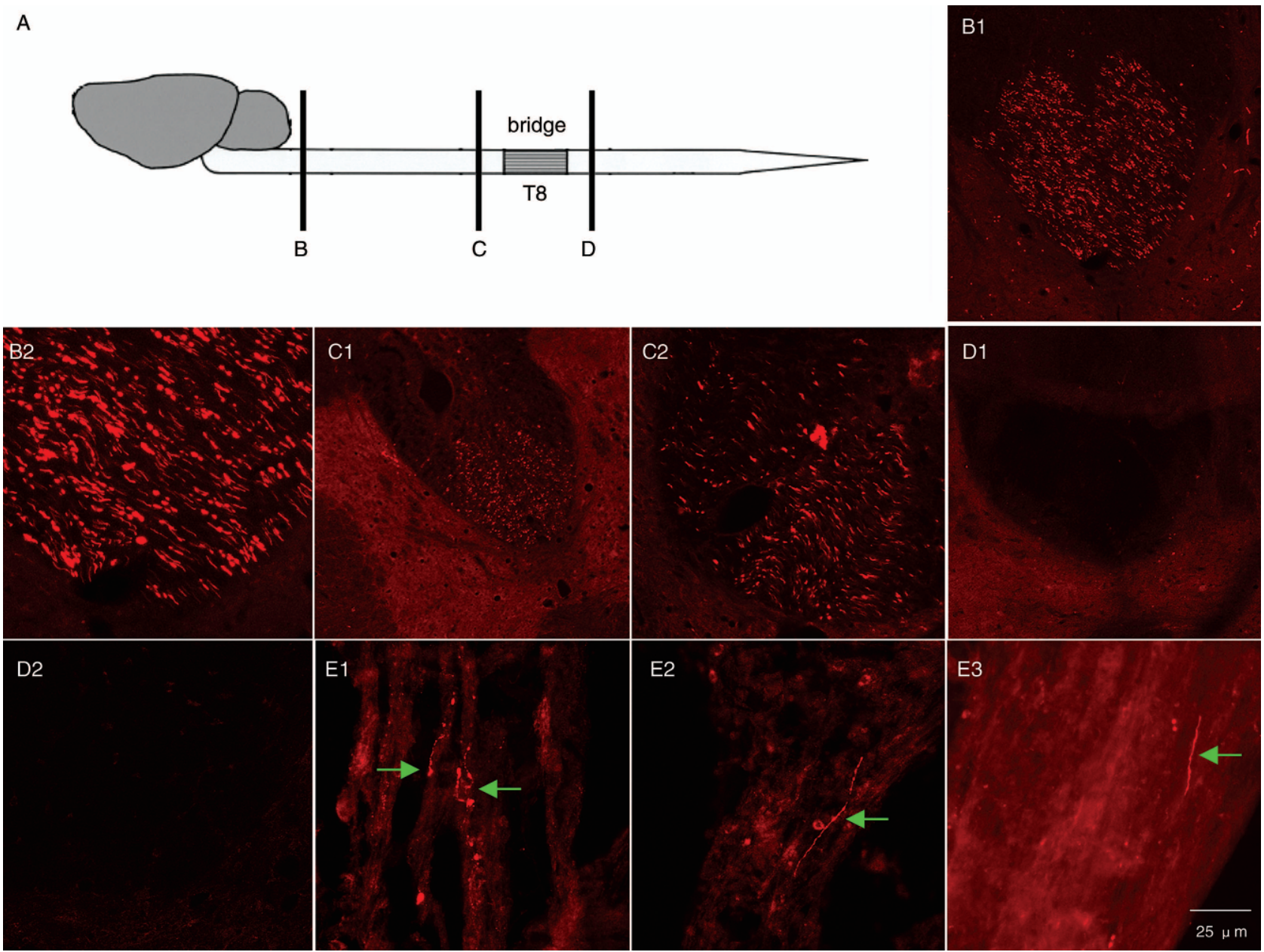

D2

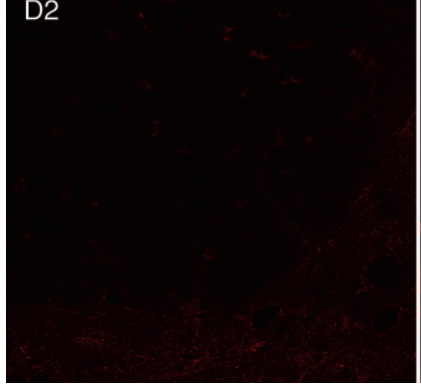

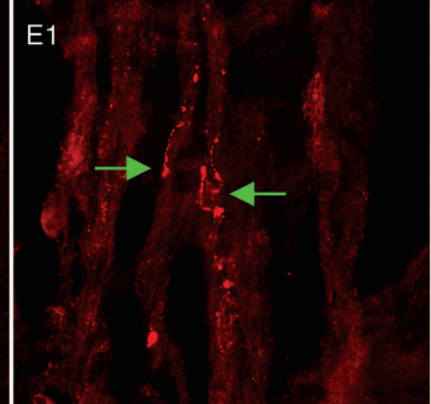

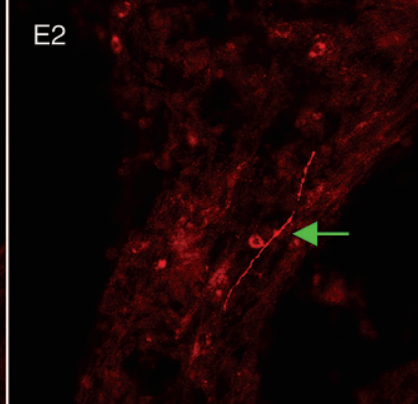

Figure 7. A small number of descending corticospinal tract axons grew into the central bridges as shown by anterograde tracing with BDA. (A-C) Cross section of spinal cord at cervical (A1, A2), thoracic just rostral to the transection site (B1, B2), and lumbar $(\mathrm{C} 1, \mathrm{C} 2)$ caudal to the transection site. No BDA-labeled fibers were detected in the caudal stump (C). Parasagittal sections were examined for BDA-labeled corticospinal tract fibers in the stumps and bridging tissue. Linear BDA-positive structures were considered to be axons (arrows in D1-D3). (D1) and (D2) are from group 1, and (D3) is from group 3, from the central bridge at the T8 transection site. In the NSPC-transplanted groups 1-3 BDA-labeled fibers were detected in the central bridge. Scale bars: $100 \mu \mathrm{m}$ (A1-C1); $25 \mu \mathrm{m}(\mathrm{A} 2-\mathrm{C} 2, \mathrm{D} 1-3)$. 

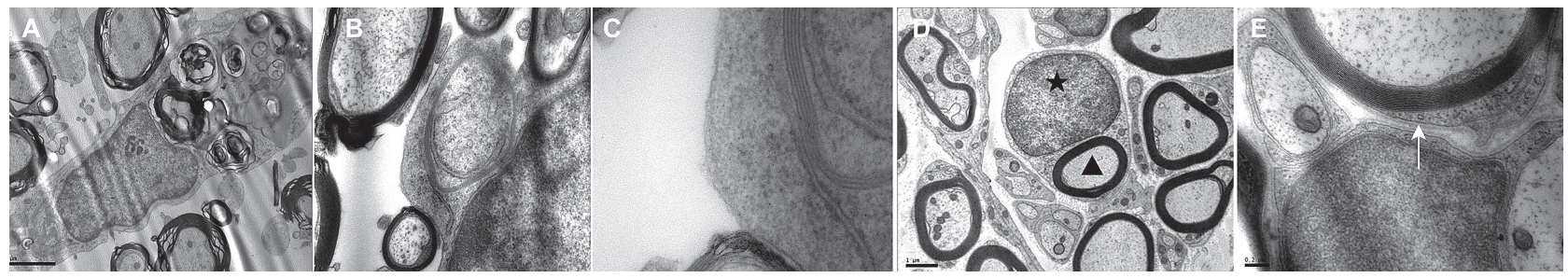

Figure 8. Twelve weeks after channel implantation, TEM of the thinnest part of the central tissue bridge confirmed abundant axonal regeneration and myelination in NgR-treated groups. (A) Large numbers of regenerated axons with varying degrees of myelination. One oligodendrocyte has myelinated several axons. (B) Another oligodendrocyte with axons. (C) Higher power view of the myelinating cell in (B) demonstrates the lack of a basal lamina and suggests that these cells are oligodendroglia. (D, E) In contrast, the one-to-one ratio of nucleus (star) to axon (triangle) and the basal lamina (arrow in E) indicates that these are Schwann cells. There were also some unmyelinated axons in (D) and (E). Scale bars: $2 \mu \mathrm{m}$ (A); $500 \mathrm{~nm}$ (B); $100 \mathrm{~nm}$ (C); $1 \mu \mathrm{m}$ (D); 0.2 $\mu \mathrm{m}(\mathrm{E})$.

were 0.296 and 0.450 , respectively, and 0.382 and 0.298, respectively, in the untreated control groups. There was no significant difference between these groups $(p>0.05)$.

\section{No Significant Improvement in Function Between Groups}

There was no significant difference in the BBB score among groups 1-6 for 12 weeks after SCT and treatment $(p>0.05)$ (Fig. 9). No animal achieved plantar placement of the paw with weight support (BBB score of 9).

\section{DISCUSSION}

This is the first report of the extramedullary implantation of chitosan channels seeded with NSPCs combined with GFs and soluble $\mathrm{NgR}$ protein after SCT. The results showed that the combination with GFs resulted in good long-term survival of NSPCs, and that GFs selectively increased NSPC differentiation into oligodendrocytes. In contrast, $\mathrm{NgR}$ significantly decreased astrocytic differentiation of NSPCs, and $\mathrm{NgR}$ alone or in combination with NSPCs significantly enhanced the total number of myelinated fibers in the bridge and increased the area of the bridges between the cord stumps. The combination of NSPCs, GFs, and NgR had a synergistic effect on bridge formation, but did not enhance functional recovery.

\section{GFs Significantly Improved the Long-Term Survival of NSPCs In Vivo}

The existence of adult CNS multipotential neural stem cells $(2,67,68)$ presents a new strategy for cell therapy to repair CNS injuries. Similar to embryonic stem cells (ESCs), adult NSPCs have shown an extensive capacity for self-renewal and multipotentiality in vitro

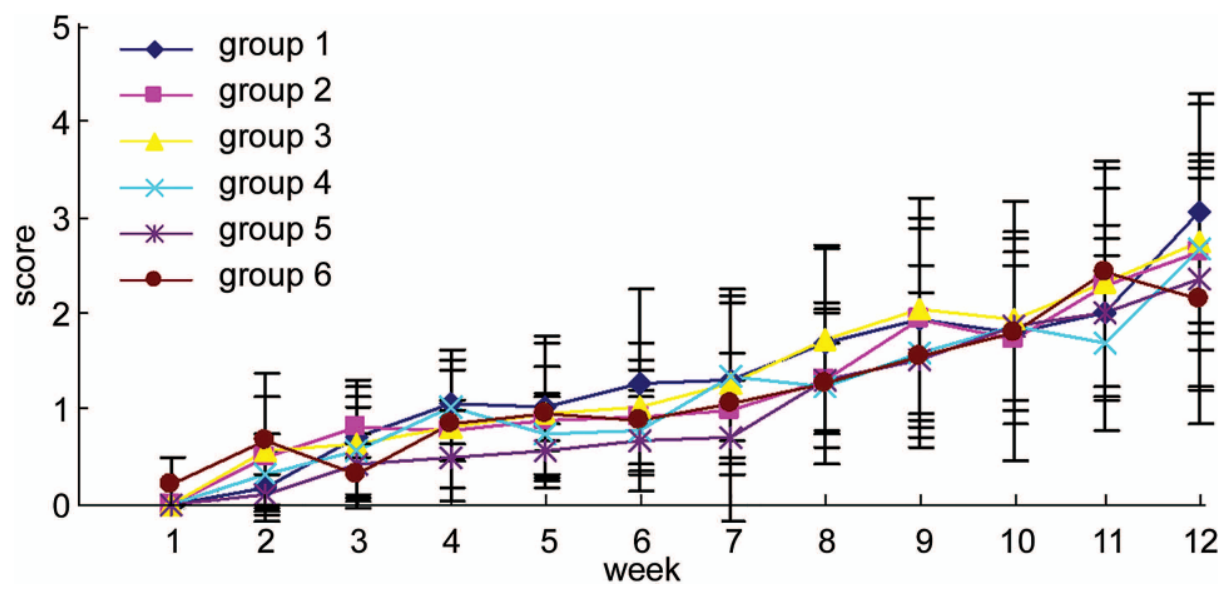

Figure 9. Functional evaluation using Basso, Beattie, Bresnahan (BBB) scoring 12 weeks after channel implantation. The data showed that there was no significant difference in recovery among any of the treated groups. Error bars indicate mean \pm SE. 
$(49,51)$, and, importantly, they obviate the potential ethical issues surrounding the use of embryonic or fetal stem cells for regenerative therapies. NSPCs have the capacity to migrate, integrate with the host tissue, and to respond to local cues for differentiation. The population of NSPCs residing in the forebrain and spinal cord is maintained for life and tissue from human transplant donors is a potential source of transplantable cells for individuals with SCI or other CNS disorders. The survival and differentiation of transplanted adult NSPCs are important considerations in assessing the potential of this strategy.

In the present study, we found that GFs such as the combination of bFGF, EGF, and PDGF significantly enhanced the survival of NSPCs whereas NgR had no positive or negative influence on the survival of NSPCs.In the present study, channels were preseeded with $1 \times 10^{6}$ cells prior to implantation and cell survival was assayed at 14 weeks posttransplantation. Group 1 had a mean survival of $2.89 \times 10^{6}$ cells, group 2 had $2.78 \times$ $10^{6}$ cells, group 3 had $1.29 \times 10^{6}$ cells, and group 7 had $1.10 \times 10^{6}$ cells, respectively. Hence, the number of surviving cells at 14 weeks posttransplantation in the GFtreated groups 1 or 2 was two to three times more than that at the beginning, whereas in the non-GF-treated groups 3 or 7 the number of surviving NSPCs was almost the same as at the beginning. In our previous study of extramedullary implanted chitosan channels in the same SCT model but without the delivery of GFs and $\mathrm{NgR}$, Nomura et al. seeded $3 \times 10^{6}$ brain-derived NSPCs per channel and found $3.31 \times 10^{6} \pm 2.03 \times 10^{6}$ cells survived at 14 weeks posttransplantation (42). The survival ratio reported by Nomura et al. is much lower than that seen in the GF-treated groups 1 and 2 but quite similar to the ratio observed in non-GF-treated groups 3 and 7 in the present study. These data suggest that the combination of bFGF, EGF, and PDGF significantly enhanced the long-term survival of NSPCs. These GFs have been shown to have beneficial effects on the proliferation and survival of NSPCs in vitro and in vivo $(15,21,26,49,67)$. EGF and bFGF are potent mitogenic factors that have been used extensively for in vitro expansion of NSPCs from the subventricular zone. Moreover, bFGF enhanced the proliferation and survival of neuronal and glial precursor cells $(36,64)$, and PDGFAA promoted the proliferation of bipotential progenitors and O-2A cells $(24,47)$.

Laminin-coated extramedullary chitosan channels also contributed to the excellent long-term survival of the NSPCs. They permit very good in vitro adhesion and create a permissive microenvironment for in vivo survival of seeded NSPCs. Therefore, biodegradable chitosan channels are a promising biomaterial for combination strategies involving stem cell transplantation.
To examine the long-term tumorigenesis of the transplanted cells (34), we used Ki67, a prototypic cell cyclerelated nuclear protein, expressed by cells in all phases of the active cell cycle $\left(\mathrm{G}_{1}, \mathrm{~S}, \mathrm{G}_{2}\right.$, and $\mathrm{M}$ phase), and found that none of the GFP-positive cells colabeled with Ki67 at 14 weeks after transplantation, indicating that the donor cells were not proliferating at that time. Also, we did not observe any signs of tumorigenesis macroscopically or microscopically at the transplant site. The lack of observed proliferation at 14 weeks supports the safety of adult NSPCs for cell-based therapies for SCI. These results are consistent with our previous short-term study, where NSPCs stained negative for Ki67 at 5 weeks postimplantation, suggesting minimal potential for tumor formation (71). In the present study some rats had a large mass of GFP-positive cells at the end of the bridges, perhaps due to the administration of GFs.

\section{Growth Factors Significantly Induce Differentiation of NSPCs Into Oligodendrocytes Especially and Also Astrocytes}

SCI results in loss of oligodendrocytes and demyelination of surviving axons. Despite the presence of endogenous neural stem cell populations within the adult spinal cord, the extent of oligodendrocyte differentiation from these endogenous precursor cells, even after infusion of exogenous growth factors (24), is not sufficient to promote remyelination after SCI. Thus, restoration of the oligodendrocyte population by cell replacement therapy is an attractive strategy to promote remyelination of regenerated axons after SCI or other disorders characterized by loss or deficiency of myelin.

In the present study, we found that brain derived NSPCs differentiated mainly into oligodendrocytes and astrocytes in this permissive environment 14 weeks after transplantation. In the GF-treated groups, NSPC mainly differentiated into CC1-positive mature oligodendrocytes $(29.41 \%$ in group 1 and $27.77 \%$ in group 2, respectively). In our previous study of extramedullary implanted chitosan channels seeded with the same adult rat brain-derived NSPCs in the same SCT model but without the delivery of GFs and $\mathrm{NgR}$, Nomura et al. found only $17.4 \%$ of the transplanted NSPCs differentiated into oligodendrocytes at 14 weeks postimplantation (42). While another study in a different SCI model but with treatment with the same GFs, Karimi-Abdolrezaee et al. (21) showed that $32.67 \%$ of the surviving transplanted brain-derived NSPCs differentiated into mature oligodendrocytes at 8 weeks after direct injection into the white matter of the spinal cord when transplanted during the subacute stage of clip compression SCI.

The comparison of these data suggests that the present combination of GFs promote preferential differentiation of brain derived NSPCs toward an oligodendrocyte 
lineage. PDGF-AA is known to stimulate the differentiation of oligodendrocytes (47), and also promotes the survival of newly formed oligodendrocytes $(7,8)$. Moreover, PDGF, in synergy with bFGF, regulates the proliferative response of adult oligodendrocyte progenitors $(15,26)$.

In contrast, we found that $\mathrm{NgR}$ significantly decreased astrocytic differentiation, but had no impact on the differentiation of oligodendrocytes and neurons. Consistent with our previous studies, no neurons were generated in any of the groups $(42,71)$. The differentiation of transplanted NSPCs primarily into glial lineages suggests that the diseased/injured spinal cord may be inhibitory to neuronal differentiation of precursor cells. Other exogenous cues from different growth factors, small molecules, oligopeptides, and biomimetic materials may be required to direct transplanted NSPCs down the neuronal pathway $(20,49,54,55,63,69,70,72)$.

\section{NgR(310)ecto-Fc Promotes Axonal Sprouting/Regeneration and Myelination}

The Nogo-66 receptor $(\mathrm{NgR})$ provides an attractive therapeutic target because of its important role, highaffinity interactions, and neural specificity. $\mathrm{NgR}$ is a novel Ig-fusion protein containing the ligand binding domain of Nogo-66 receptor 1 and was reported to block the inhibitory effect of all three myelin-derived inhibitors in vitro and in vivo. Li et al. (29) delivered $\mathrm{NgR}$ intrathecally through an osmotic pump for 28 days to the midthoracic region of rats with overhemisection SCI, and found that the degree of axonal sprouting was more robust than with treatment with the Nogo-66-specific antagonist peptide (Nogo extracellular peptide, residues 1-40; NEP1-40) (16). The axonal sprouting of corticospinal and raphespinal fibers in NgR-treated animals correlated with improved spinal cord electrical conduction and improved locomotion. Ji et al. (18) administered $\mathrm{NgR}$ intrathecally for 28 days to rats with $\mathrm{T} 7$ dorsal hemisection, and found that it increased axonal sprouting and the number of axons contacting motor neurons in the ventral horn gray matter caudal to the lesion. Lee et al. also reported that intracerebroventricular administration of $\mathrm{NgR}$ in rats with middle cerebral artery occlusion enhanced both the recovery of motor skills and corticofugal axonal plasticity (27).

$\mathrm{NgR}$ may be more effective than agents that block a single inhibitory myelin protein. For example, the antiNogoA antibody, IN-1, and the Nogo-66-derived antagonist peptide (NEP1-40), both of which reversed CNS myelin-dependent inhibition of neurite outgrowth, promoted axonal regeneration, and improved functional recovery in experimental SCI. However, these reagents only target a single myelin protein, Nogo, and may not facilitate maximal $\mathrm{CNS}$ axonal regeneration because other inhibitors such as MAG and OMgp may be present
$(5,16,30,58)$. Reagents that block all three ligands may maximize axonal regeneration.

In the present study, the NgR-treated groups showed large numbers of NF200-positive axons not only in the central bridges but also in the lateral bridges. $\mathrm{NgR}$ alone (group 5) produced a significant increase in total number of myelinated fibers $(3,000 \pm 854.7)$ compared with that of the empty-channel group (group 6, 622 \pm 286.3 , Table 3), indicating that this agent alone could promote axonal sprouting/regeneration. The combination of $\mathrm{NgR}$ with NSPCs (group 3) also significantly enhanced the total number of myelinated fibers $(2,285 \pm 1,727.8)$. In our previous study of extramedullary implanted chitosan channels seeded with the same adult rat brain-derived NSPCs in the same SCT model but without GFs and $\mathrm{NgR}$, our group reported that the total number of myelinated fibers in the brain-derived NSPCs seeded channel groups and the empty-channel groups was only $429 \pm 198$ and $666 \pm 370$, respectively $(p>0.05)$, and that the myelinated fibers were only concentrated in the central bridges, while no myelinated fibers were seen in the lateral bridges (42). Also, comparison of the two studies suggests that local delivery of $\mathrm{NgR}$ can significantly enhance axonal sprouting/regeneration without changing the total number of myelinated fibers in the empty-channel groups $(622 \pm 286$ presently and $666 \pm$ 370 previously).

A small number of descending corticospinal tract axons grew into the central bridges as shown by anterograde tracing with BDA in the NSPC-transplanted groups. Although these BDA-labeled fibers were too few for accurate quantitation, they were not seen in the previous study $(42,59,60)$. The low serum titer of anti$\mathrm{NgR}$ antibody after 4 or 12 weeks indicates little immunological reaction and suggests that this agent is safe.

\section{Origin of Regenerated Axons}

In the present study, we found that large numbers of NF200-positive axons regenerated in the lateral and central bridges in the NgR-treated groups. These regenerated axons were often parallel to the channel wall, and some even migrated through the catheter hole in the channel, and there were large numbers of GFP-positive NSPCs aligned linearly and closely related to them. It is possible that these regenerated axons act as a biological microfiber scaffold to provide a three-dimensional support for the adhesion, migration, proliferation, and differentiation of NSPCs, especially to guide their migration into the central part of the stumps.

We found that the majority of the axons in all the groups were immunolabeled with CGRP (data not shown), and ranged between 3.6 and $4.3 \mu \mathrm{m}$ in diameter, which is much thicker than the most of the axons in the the spinal cord. This is consistent with our previous 
findings $(40,42)$. Also, retrograde labeling with FG confirmed that most of the axons in the bridges did not originate from brain stem motor nuclei. Together, these features suggest that the majority of the regenerated axons in the channels originate from adjacent host neurons such as the dorsal root ganglia and local motor neurons rather than from host central sensory or motor tracts that are generally thinner $(40,42)$.

\section{CONCLUSIONS}

Compared with our previous channel-based studies, the current combinatory strategy found that GFs significantly improved the survival of NSPCs and selectively induced differentiation into oligodendrocytes. NgR significantly decreased astrocytic differentiation and also promoted axonal sprouting/regeneration and myelination. The combination of NgR with NSPCs significantly enhanced axonal sprouting/regeneration and the area of the bridge that grew between the stumps of the transected spinal cord, and the addition of GFs had a synergistic effect on bridge formation. Thus, these combination strategies show a promising potential for repair after major SCI. However, there was no functional benefit. We are currently developing these combination strategies in the context of temporally controlled, localized release of proteins and growth factors from chitosan channels or injectable hydrogel, oligopeptide modified chitosan channels, chitosan or photolabile hydrogel based multiple-channel scaffolds to enhance axonal regeneration and functional recovery after SCI $(23,33,50,69,70)$.

ACKNOWLEDGMENTS: This work was supported by the Natural Sciences and Engineering Research Council (NSERC), the Canadian Institutes for Health Research, and the Program for New Century Excellent Talents in University from the Ministry of Education of China (NCET-05-0648), and the National Natural Science Foundation of China (81171684, 30973027). We thank Rita Van Bendegem, Linda Lee, Howard Kim, Iris Kulbatski, Sheer Ramjohn, Peter Poon, and Yongchao Wu for their excellent technical assistance. The authors declare no conflict of interest.

\section{REFERENCES}

1. Akesson, E.; Sandelin, M.; Kanaykina, N.; Aldskogius, H.; Kozlova, E. N. Long-term survival, robust neuronal differentiation, and extensive migration of human forebrain stem/progenitor cells transplanted to the adult rat dorsal root ganglion cavity. Cell Transplant. 17:1115$1123 ; 2008$.

2. Anthes, D. L.; Theriault, E.; Tator, C. H. Ultrastructural evidence for arteriolar vasospasm after spinal cord trauma. Neurosurgery 39:804-814; 1996.

3. Basso, D. M.; Beattie, M. S.; Bresnahan, J. C. A sensitive and reliable locomotor rating scale for open field testing in rats. J. Neurotrauma 12:1-21; 1995.

4. Bradbury, E. J.; Moon, L. D.; Popat, R. J.; King, V. R.; Bennett, G. S.; Patel, P. N.; Fawcett, J. W.; McMahon, $\mathrm{S}$. B. Chondroitinase $\mathrm{ABC}$ promotes functional recovery after spinal cord injury. Nature 416:636-640; 2002.
5. Bregman, B. S.; Kunkel-Bagden, E.; Schnell, L.; Dai, H. N.; Gao, D.; Schwab, M. E. Recovery from spinal cord injury mediated by antibodies to neurite growth inhibitors. Nature 378:498-501; 1995.

6. Bunge, M. B. Novel combination strategies to repair the injured mammalian spinal cord. J. Spinal Cord Med. 31: 262-269; 2008.

7. Butt, A. M.; Hornby, M. F.; Ibrahim, M.; Kirvell, S.; Graham, A.; Berry, M. PDGF-alpha receptor and myelin basic protein mRNAs are not coexpressed by oligodendrocytes in vivo: A double in situ hybridization study in the anterior medullary velum of the neonatal rat. Mol. Cell. Neurosci. 8:311-322; 1997.

8. Butt, A. M.; Hornby, M. F.; Kirvell, S.; Berry, M. Platelet-derived growth factor delays oligodendrocyte differentiation and axonal myelination in vivo in the anterior medullary velum of the developing rat. J. Neurosci. Res. 48:588-596; 1997.

9. Cafferty, W. B.; McGee, A. W.; Strittmatter, S. M. Axonal growth therapeutics: Regeneration or sprouting or plasticity? Trends Neurosci. 31:215-220; 2008.

10. Chen, K.; Hughes, S. M.; Connor, B. Neural progenitor cells derived from the adult rat subventricular zone: Characterization and transplantation. Cell Transplant. 16:799810; 2007.

11. Curristin, S. M.; Cao, A.; Stewart, W. B.; Zhang, H.; Madri, J. A.; Morrow, J. S.; Ment, L. R. Disrupted synaptic development in the hypoxic newborn brain. Proc. Natl. Acad. Sci. USA 99:15729-15734; 2002.

12. Domeniconi, M.; Cao, Z.; Spencer, T.; Sivasankaran, R.; Wang, K.; Nikulina, E.; Kimura, N.; Cai, H.; Deng, K.; Gao, Y.; He, Z.; Filbin, M. Myelin-associated glycoprotein interacts with the Nogo66 receptor to inhibit neurite outgrowth. Neuron 35:283-290; 2002.

13. Erschbamer, M.; Pernold, K.; Olson, L. Inhibiting epidermal growth factor receptor improves structural, locomotor, sensory, and bladder recovery from experimental spinal cord injury. J. Neurosci. 27:6428-6435; 2007.

14. Freier, T.; Montenegro, R.; Shan Koh, H.; Shoichet, M. S. Chitin-based tubes for tissue engineering in the nervous system. Biomaterials 26:4624-4632; 2005.

15. Frost, E. E.; Nielsen, J. A.; Le, T. Q.; Armstrong, R. C. PDGF and FGF2 regulate oligodendrocyte progenitor responses to demyelination. J. Neurobiol. 54:457-472; 2003.

16. GrandPre, T.; Li, S.; Strittmatter, S. M. Nogo-66 receptor antagonist peptide promotes axonal regeneration. Nature 417:547-551; 2002.

17. Hunt, D. P.; Irvine, K. A.; Webber, D. J.; Compston, D. A.; Blakemore, W. F.; Chandran, S. Effects of direct transplantation of multipotent mesenchymal stromal/stem cells into the demyelinated spinal cord. Cell Transplant. $17: 865-873 ; 2008$.

18. Ji, B.; Li, M.; Budel, S.; Pepinsky, R. B.; Walus, L.; Engber, T. M.; Strittmatter, S. M.; Relton, J. K. Effect of combined treatment with methylprednisolone and soluble Nogo-66 receptor after rat spinal cord injury. Eur. J. Neurosci. 22:587-594; 2005.

19. Jimenez Hamann, M. C.; Tator, C. H.; Shoichet, M. S. Injectable intrathecal delivery system for localized administration of EGF and FGF-2 to the injured rat spinal cord. Exp. Neurol. 194:106-119; 2005.

20. Johnson, P. J.; Tatara, A.; Shiu, A.; Sakiyama-Elbert, S. E. Controlled release of neurotrophin-3 and platelet derived growth factor from fibrin scaffolds containing neural 
progenitor cells enhances survival and differentiation into neurons in a subacute model of SCI. Cell Transplant. 19: 89-101; 2010.

21. Karimi-Abdolrezaee, S.; Eftekharpour, E.; Wang, J.; Morshead, C. M.; Fehlings, M. G. Delayed transplantation of adult neural precursor cells promotes remyelination and functional neurological recovery after spinal cord injury. J. Neurosci. 26:3377-3389; 2006.

22. Katayama, Y.; Montenegro, R.; Freier, T.; Midha, R.; Belkas, J. S.; Shoichet, M. S. Coil-reinforced hydrogel tubes promote nerve regeneration equivalent to that of nerve autografts. Biomaterials 27:505-518; 2006.

23. Kim, B. G.; Hwang, D. H.; Lee, S. I.; Kim, E. J.; Kim, S. U. Stem cell-based cell therapy for spinal cord injury. Cell Transplant. 16:355-364; 2007.

24. Kojima, A.; Tator, C. H. Intrathecal administration of epidermal growth factor and fibroblast growth factor 2 promotes ependymal proliferation and functional recovery after spinal cord injury in adult rats. J. Neurotrauma 19: 223-238; 2002.

25. Kulbatski, I.; Mothe, A. J.; Nomura, H.; Tator, C. H. Endogenous and exogenous CNS derived stem/progenitor cell approaches for neurotrauma. Curr. Drug Targets 6: 111-126; 2005.

26. Lachapelle, F.; Avellana-Adalid, V.; Nait-Oumesmar, B.; Baron-Van Evercooren, A. Fibroblast growth factor-2 (FGF-2) and platelet-derived growth factor AB (PDGF $\mathrm{AB})$ promote adult SVZ-derived oligodendrogenesis in vivo. Mol. Cell. Neurosci. 20:390-403; 2002.

27. Lee, J. K.; Kim, J. E.; Sivula, M.; Strittmatter, S. M. Nogo receptor antagonism promotes stroke recovery by enhancing axonal plasticity. J. Neurosci. 24:6209-6217; 2004.

28. Li, S.; Kim, J. E.; Budel, S.; Hampton, T. G.; Strittmatter, S. M. Transgenic inhibition of Nogo-66 receptor function allows axonal sprouting and improved locomotion after spinal injury. Mol. Cell. Neurosci. 29:26-39; 2005.

29. Li, S.; Liu, B. P.; Budel, S.; Li, M.; Ji, B.; Walus, L.; Li, W.; Jirik, A.; Rabacchi, S.; Choi, E.; Worley, D.; Sah, D. W.; Pepinsky, B.; Lee, D.; Relton, J.; Strittmatter, S. M. Blockade of Nogo-66, myelin-associated glycoprotein, and oligodendrocyte myelin glycoprotein by soluble Nogo-66 receptor promotes axonal sprouting and recovery after spinal injury. J. Neurosci. 24:10511-10520; 2004.

30. Li, S.; Strittmatter, S. M. Delayed systemic Nogo-66 receptor antagonist promotes recovery from spinal cord injury. J. Neurosci. 23:4219-4227; 2003.

31. Li, W.; Walus, L.; Rabacchi, S. A.; Jirik, A.; Chang, E.; Schauer, J.; Zheng, B. H.; Benedetti, N. J.; Liu, B. P.; Choi, E.; Worley, D.; Silvian, L.; Mo, W.; Mullen, C.; Yang, W.; Strittmatter, S. M.; Sah, D. W.; Pepinsky, B.; Lee, D. H. A neutralizing anti-Nogo66 receptor monoclonal antibody reverses inhibition of neurite outgrowth by central nervous system myelin. J. Biol. Chem. 279: 43780-43788; 2004.

32. Liu, B. P.; Fournier, A.; GrandPre, T.; Strittmatter, S. M. Myelin-associated glycoprotein as a functional ligand for the Nogo-66 receptor. Science 297:1190-1193; 2002.

33. Luo, Y.; Shoichet, M. S. A photolabile hydrogel for guided three-dimensional cell growth and migration. Nat. Mater. 3:249-253; 2004.

34. Matsuda, R.; Yoshikawa, M.; Kimura, H.; Ouji, Y.; Nakase, H.; Nishimura, F.; Nonaka, J.; Toriumi, H.; Yamada, S.; Nishiofuku, M.; Moriya, K.; Ishizaka, S.; Nakamura, M.; Sakaki, T. Cotransplantation of mouse embryonic stem cells and bone marrow stromal cells following spinal cord injury suppresses tumor development. Cell Transplant. 18:39-54; 2009.

35. McGee, A. W.; Strittmatter, S. M. The Nogo-66 receptor: Focusing myelin inhibition of axon regeneration. Trends Neurosci. 26:193-198; 2003.

36. Meijs, M. F.; Timmers, L.; Pearse, D. D.; Tresco, P. A.; Bates, M. L.; Joosten, E. A.; Bunge, M. B.; Oudega, M. Basic fibroblast growth factor promotes neuronal survival but not behavioral recovery in the transected and Schwann cell implanted rat thoracic spinal cord. J. Neurotrauma 21: 1415-1430; 2004.

37. Mothe, A. J.; Kulbatski, I.; Parr, A.; Mohareb, M.; Tator, C. H. Adult spinal cord stem/progenitor cells transplanted as neurospheres preferentially differentiate into oligodendrocytes in the adult rat spinal cord. Cell Transplant. 17: 735-751; 2008.

38. Mothe, A. J.; Tator, C. H. Transplanted neural stem/progenitor cells generate myelinating oligodendrocytes and Schwann cells in spinal cord demyelination and dysmyelination. Exp. Neurol. 213:176-190; 2008.

39. Nomura, H.; Baladie, B.; Katayama, Y.; Morshead, C. M.; Shoichet, M. S.; Tator, C. H. Delayed implantation of intramedullary chitosan channels containing nerve grafts promotes extensive axonal regeneration after spinal cord injury. Neurosurgery 63:127-143; 2008.

40. Nomura, H.; Katayama, Y.; Shoichet, M. S.; Tator, C. H. Complete spinal cord transection treated by implantation of a reinforced synthetic hydrogel channel results in syringomyelia and caudal migration of the rostral stump. Neurosurgery 59:183-192; 2006.

41. Nomura, H.; Tator, C. H.; Shoichet, M. S. Bioengineered strategies for spinal cord repair. J. Neurotrauma 23:496507; 2006.

42. Nomura, H.; Zahir, T.; Kim, H.; Katayama, Y.; Kulbatski, I.; Morshead, C. M.; Shoichet, M. S.; Tator, C. H. Extramedullary chitosan channels promote survival of transplanted neural stem and progenitor cells and create a tissue bridge after complete spinal cord transection. Tissue Eng. Part A 14:649-665; 2008.

43. Parr, A. M.; Kulbatski, I.; Tator, C. H. Transplantation of adult rat spinal cord stem/progenitor cells for spinal cord injury. J. Neurotrauma 24:835-845; 2007.

44. Parr, A. M.; Kulbatski, I.; Zahir, T.; Wang, X.; Yue, C.; Keating, A.; Tator, C. H. Transplanted adult spinal cordderived neural stem/progenitor cells promote early functional recovery after rat spinal cord injury. Neuroscience 155:760-770; 2008

45. Parr, A. M.; Tator, C. H. Intrathecal epidermal growth factor and fibroblast growth factor-2 exacerbate meningeal proliferative lesions associated with intrathecal catheters. Neurosurgery 60:926-933; 2007.

46. Piotrowicz, A.; Shoichet, M. S. Nerve guidance channels as drug delivery vehicles. Biomaterials 27:2018-2027; 2006.

47. Raff, M. C.; Lillien, L. E.; Richardson, W. D.; Burne, J. F.; Noble, M. D. Platelet-derived growth factor from astrocytes drives the clock that times oligodendrocyte development in culture. Nature 333:562-565; 1988.

48. Raisman, G.; Li, Y. Repair of neural pathways by olfactory ensheathing cells. Nat. Rev. Neurosci. 8:312-319; 2007.

49. Reynolds, B. A.; Weiss, S. Generation of neurons and astrocytes from isolated cells of the adult mammalian central nervous system. Science 255:1707-1710; 1992.

50. Reynolds, L. F.; Bren, M. C.; Wilson, B. C.; Gibson, 
G. D.; Shoichet, M. S.; Murphy, R. J. Transplantation of porous tubes following spinal cord transection improves hindlimb function in the rat. Spinal Cord 46:58-64; 2008.

51. Richards, L. J.; Kilpatrick, T. J.; Bartlett, P. F. De novo generation of neuronal cells from the adult mouse brain. Proc. Natl. Acad. Sci. USA 89:8591-8595; 1992.

52. Santos-Benito, F. F.; Muñoz-Quiles, C.; Ramón-Cueto, A. Long-term care of paraplegic laboratory mammals. J. Neurotrauma 23:521-536; 2006.

53. Savio, T.; Schwab, M. E. Rat CNS white matter, but not gray matter, is nonpermissive for neuronal cell adhesion and fiber outgrowth. J. Neurosci. 9:1126-1133; 1989.

54. Silva, G. A.; Czeisler, C.; Niece, K. L.; Beniash, E.; Harrington, D. A.; Kessler, J. A.; Stupp, S. I. Selective differentiation of neural progenitor cells by high-epitope density nanofibers. Science 303:1352-1355; 2004.

55. Skaper, S. D. Neuronal growth-promoting and inhibitory cues in neuroprotection and neuroregeneration. Ann. NY Acad. Sci. 1053:376-385; 2005.

56. Snow, D. M.; Lemmon, V.; Carrino, D. A.; Caplan, A. I.; Silver, J. Sulfated proteoglycans in astroglial barriers inhibit neurite outgrowth in vitro. Exp. Neurol. 109:111130; 1990.

57. Tator, C. H. Review of treatment trials in human spinal cord injury: Issues, difficulties, and recommendations. Neurosurgery 59:957-982; 2006.

58. Thallmair, M.; Metz, G. A.; Z'Graggen, W. J.; Raineteau, O.; Kartje, G. L.; Schwab, M. E. Neurite growth inhibitors restrict plasticity and functional recovery following corticospinal tract lesions. Nat. Neurosci. 1:124-131; 1998.

59. Tsai, E. C.; Dalton, P. D.; Shoichet, M. S.; Tator, C. H. Synthetic hydrogel guidance channels facilitate regeneration of adult rat brainstem motor axons after complete spinal cord transection. J. Neurotrauma 21:789-804; 2004.

60. Tsai, E. C.; Dalton, P. D.; Shoichet, M. S.; Tator, C. H. Matrix inclusion within synthetic hydrogel guidance channels improves specific supraspinal and local axonal regeneration after complete spinal cord transection. Biomaterials 27:519-533; 2006.

61. Tsai, E. C.; Tator, C. H. Neuroprotection and regeneration strategies for spinal cord repair. Curr. Pharm. Des. 11: 1211-1222; 2005.

62. Tsai, E. C.; van Bendegem, R. L.; Hwang, S. W.; Tator, C. H. A novel method for simultaneous anterograde and retrograde labeling of spinal cord motor tracts in the same animal. J. Histochem. Cytochem. 49:1111-1122; 2001.

63. Tysseling, V. M.; Sahni, V.; Pashuck, E. T.; Birch, D.; Hebert, A.; Czeisler, C.; Stupp, S. I.; Kessler, J. A. Selfassembling peptide amphiphile promotes plasticity of serotonergic fibers following spinal cord injury. J. Neurosci. Res. 88:3161-3170; 2010.

64. Vescovi, A. L.; Reynolds, B. A.; Fraser, D. D.; Weiss, S. bFGF regulates the proliferative fate of unipotent (neuronal) and bipotent (neuronal/astroglial) EGF-generated CNS progenitor cells. Neuron 11:951-966; 1993.

65. Wang, K. C.; Koprivica, V.; Kim, J. A.; Sivasankaran, R.; Guo, Y.; Neve, R. L.; He, Z. Oligodendrocyte-myelin glycoprotein is a Nogo receptor ligand that inhibits neurite outgrowth. Nature 417:941-944; 2002.

66. Weidner, N.; Ner, A.; Salimi, N.; Tuszynski, M. H. Spontaneous corticospinal axonal plasticity and functional recovery after adult central nervous system injury. Proc. Natl. Acad. Sci. USA 98:3513-3518; 2001.

67. Weiss, S.; Dunne, C.; Hewson, J.; Wohl, C.; Wheatley, M.; Peterson, A. C.; Reynolds, B. A. Multipotent CNS stem cells are present in the adult mammalian spinal cord and ventricular neuroaxis. J. Neurosci. 16:7599-7609; 1996.

68. Weiss, S.; Reynolds, B. A.; Vescovi, A. L.; Morshead, C.; Craig, C. G.; van der Kooy, D. Is there a neural stem cell in the mammalian forebrain? Trends Neurosci. 19:387$393 ; 1996$

69. Yu, L. M.; Kazazian, K.; Shoichet, M. S. Peptide surface modification of methacrylamide chitosan for neural tissue engineering applications. J. Biomed. Mater. Res. A 82: 243-255; 2007.

70. Yu, L. M.; Wosnick, J. H.; Shoichet, M. S. Miniaturized system of neurotrophin patterning for guided regeneration. J. Neurosci. Methods 171:253-263; 2008.

71. Zahir, T.; Nomura, H.; Guo, X. D.; Kim, H.; Tator, C.; Morshead, C.; Shoichet, M. Bioengineering neural stem/ progenitor cell-coated tubes for spinal cord injury repair. Cell Transplant. 17:245-254; 2008.

72. Zhang, L.; Gu, S.; Zhao, C.; Wen, T. Combined treatment of neurotrophin-3 gene and neural stem cells is propitious to functional recovery after spinal cord injury. Cell Transplant. 16:475-481; 2007. 
Delivered by Ingenta to: University of Toronto

IP: 142.150.192.154 On: Tue, 01 Nov $201618: 37: 18$

Article(s) and/or figure(s) cannot be used for resale. Please use proper citation format when citing this article including the DOI, publisher reference, volume number and page location. 